\title{
ASYMPTOTIC REDUCTION OF A LITHIUM-ION POUCH CELL MODEL*
}

\author{
ROBERT TIMMS ${ }^{\dagger}$, SCOTT G. MARQUIS ${ }^{\dagger}$, VALENTIN SULZER $^{\S}$, COLIN P. PLEASE $^{\dagger}$, \\ AND S. JONATHAN CHAPMAN ${ }^{\dagger}$
}

\begin{abstract}
A three-dimensional model of a single-layer lithium-ion pouch cell is presented which couples conventional porous electrode theory describing cell electrochemical behavior with an energy balance describing cell thermal behavior. Asymptotic analysis of the model is carried out by exploiting the small aspect ratio typical of pouch cell designs. The analysis reveals the scaling that results in a distinguished limit and highlights the role played by the electrical conductivities of the current collectors. The resulting model comprises a collection of one-dimensional models for the through-cell electrochemical behavior which are coupled via two-dimensional problems for the Ohmic and thermal behavior in the planar current collectors. A further limit is identified which reduces the problem to a single volume-averaged through-cell model, greatly reducing the computational complexity. Numerical simulations are presented which illustrate and validate the asymptotic results.
\end{abstract}

Key words. battery, reduced order model, lithium ion, porous electrode theory, thermal

AMS subject classifications. 78A57, 35B40, 35B20

DOI. $10.1137 / 20 \mathrm{M} 1336898$

1. Introduction. Lithium-ion batteries are one of the most widely used technologies for energy storage, with applications ranging from portable electronics to electric vehicles $[38,35,1]$. Due to their popularity, there is a continued interest in the development of mathematical models that can efficiently and accurately describe the behavior observed during lithium-ion battery operation. Such models often provide a simplified one-dimensional description of the electrochemical behavior in the through-cell direction, justified by the assumption that the behavior in the remaining two dimensions is uniform. However, larger-sized batteries, such as those used in the electric vehicle sector, exhibit nonuniform behavior in the current and temperature distribution, which can adversely affect battery performance and life span $[20,9,21]$. In particular, local variations in the temperature may lead to cells aging in a nonuniform manner [33]. A particularly striking example of nonuniform behavior can be seen in Figure 2 of [4], which depicts extremely nonuniform lithiation in the negative electrode of a pouch cell. There is a need to better understand the origins of this nonuniformity, that is, how material properties, cell geometry, and operating conditions can give rise to local changes in the cell potential and temperature.

Since the pioneering work of Newman $[27,26,8]$, who developed a continuum description of porous electrode behavior, there has been a large body of work devoted to the mathematical modeling of batteries $[13,30]$. Not all existing models are one-

\footnotetext{
*Received by the editors May 8, 2020; accepted for publication (in revised form) February 16, 2021; published electronically May 4, 2021.

https://doi.org/10.1137/20M1336898

Funding: This work was supported by the EPSRC Centre for Doctoral Training in Industrially Focused Mathematical Modelling (EP/L015803/1) in collaboration with Siemens Corporate Technology and BBOXX Ltd. This work was also supported by The Faraday Institution through grant EP/S003053/1, FIRG003.

${ }^{\dagger}$ Mathematical Institute, University of Oxford, Oxford OX2 6GG, UK (timms@maths.ox.ac.uk, marquis@maths.ox.ac.uk, please@maths.ox.ac.uk, chapman@maths.ox.ac.uk).

‡The Faraday Institution, Didcot, OX11 0RA, UK.

$\S$ Department of Mechanical Engineering, University of Michigan, Ann Arbor, MI 48109-2133 USA (vsulzer@umich.edu).
} 
dimensional - the multiscale and multidimensional nature of the problem has also been accounted for in the literature (e.g., $[20,10,2,15,19,28]$ ), with many models based on extensions or adaptations of the porous electrode model developed by Doyle, Fuller, and Newman [8] (the DFN model), or reductions thereof.

While fully coupled three-dimensional electrochemical and thermal models provide useful information for predicting cell behavior, they are often too computationally expensive to be practically useful, and simplifications must be made. One approach is to introduce separate computational domains for each of the length scales of interest, as in the multiscale multidimensional (MSMD) model developed at the National Renewable Energy Laboratory [18]. The MSMD model provides a modular framework within which battery physics can be resolved across disparate time and length scales and provides a means of efficiently transferring information between scales. Another approach is to treat the electrochemical problem as a network of resistors, coupled to a three-dimensional thermal model [12, 22]. A current-voltage relation is given for each of the resistors in the network, which can either be a complicated description based on porous electrode theory [22] or a simplified description, such as a nonlinear resistor fitted to an electrochemical model [12] or to data [19]. This approach reduces the three-dimensional electrochemical model to a system of one-dimensional electrochemical models coupled via a two-dimensional electrical problem in the current collectors, and a three-dimensional thermal model across the entire cell.

Such simplifications, sometimes referred to as "potential pair" models, are usually made in an ad-hoc manner (e.g., [20, 12, 22]). In this paper, we provide a systematic asymptotic reduction of a full three-dimensional pouch-cell model for large current collector conductivity and small aspect ratio, identifying the parameter regimes in which such a reduction is possible. We will find that there are two distinguished limits: one in which the model reduces to a set of through-cell one-dimensional models coupled through a two-dimensional problem for the boundary conditions, and a second in which only a single through-cell one-dimensional problem needs to be solved, with an additional two-dimensional problem needed to calculate an in-series resistance. We focus our attention on a rectangular pouch-cell geometry, but a similar analysis can be performed for other cell geometries, such as those found in cylindrical or prismatic cells.

The paper is laid out as follows. In section 2 we present the governing equations for the full three-dimensional model, expressed in terms of dimensionless variables. Full details of the dimensional model may be found in the supplementary material. In section 3, we present an asymptotic reduction of the model, while in section 4 we compare numerical solutions of the full and reduced models and discuss the results. Finally, in section 5, we draw our conclusions.

2. Model equations. We consider a single-layer lithium-ion pouch cell, which consists of both negative and positive current collectors, between which a negative electrode, a porous separator, and a positive electrode are sandwiched, as shown schematically in Figure 1. Each electrode is a porous medium, comprising active material particles, in which lithium is stored, held together with a binder. The binder material is electrically conducting and acts to maintain electrical connectivity between the active material particles and the current collectors. Both electrodes and the porous separator are flooded with electrolyte, which carries ionic charge. During operation, a current is drawn from the cell via tabs connected to each current collector, which are depicted as rectangular protrusions in Figure 1. For readers unfamiliar with lithiumion batteries and their construction, an excellent introduction can be found in [29]. 


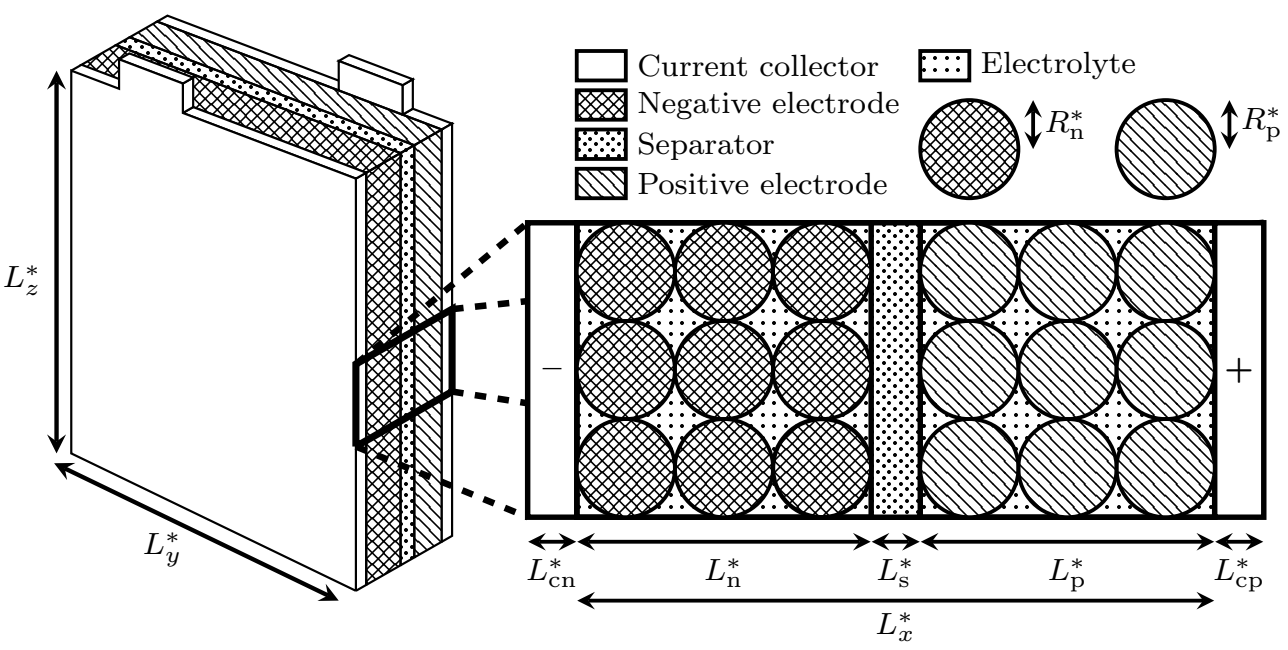

FIG. 1. Sketch of the three-dimensional pouch-cell model.

The electrochemical model developed here is based on the DFN model for porous electrodes $[27,26,8]$. This model has become the standard choice for describing the behavior of lithium-ion batteries $[11,26,13,30]$ and comprises equations for mass and charge conservation in the solid (active material and binder) and liquid (electrolyte) phases. Thermal effects may be incorporated by introducing equations describing the balance of thermal energy $[14,3]$. The model can be formally derived from a microscopic description of electrochemical processes through volume-averaging or homogenization techniques [40,31,34], but we do not give the details here.

Often such homogenization techniques result in a model posed on the macroscale with effective properties which depend on the microscale geometry. However, due to relatively slow diffusion in the particles, the DFN model retains a microscopic description of mass transport within the active material particles, which must be solved alongside macroscopic equations for charge transport in the solid material, and charge and mass transport within the electrolyte. In order to simplify the microscale model it is standard to assume that the active material particles may be treated as spheres, and that behavior within the particles is spherically symmetric. We adopt this standard assumption, but note that the analysis could be easily extended to account for alternative particle shapes (e.g., [39]). It is the combination of a onedimensional macroscale equation coupled with a one-dimensional (radial) microscopic equation which gives rise to the alternative model name of "pseudo-two-dimensional" (often abbreviated to P2D).

It is straightforward to apply the principles of the DFN model to develop a full three-dimensional model of a lithium-ion pouch cell, as illustrated in Figure 1. The model comprises the traditional DFN components of a porous negative electrode, separator, and positive electrode, each extended to three dimensions, as well as two additional components: a negative current collector and a positive current collector. We model the current collectors as Ohmic conductors. We assume a uniform current density is drawn from the positive tab, while the potential on the negative tab is uniform and set to a reference value of $0 \mathrm{~V}$. The terminal voltage is then defined as the potential averaged over the positive tab. Because thermal effects are of particular interest in the study of pouch cells, we extend the DFN model to include an equation 
for energy conservation in each cell component, accounting for the various forms of heating and cooling which occur in the cell during operation [3]. The dimensionless model equations are summarized in section 2.2 and are described in further detail in the supplementary material.

2.1. Notation. Before stating the governing equations we comment on our notation. Throughout we use a superscript ${ }^{*}$ to denote dimensional quantities. We denote electric potentials by $\phi$, current densities by $\boldsymbol{i}$, lithium concentrations ${ }^{1}$ by $c$, molar fluxes by $\boldsymbol{N}$, and temperatures by $T$. To distinguish potential, fluxes, and concentrations in the electrolyte from those in the solid phase of the electrode, we use a subscript e for electrolyte variables and a subscript $\mathrm{s}$ for solid phase variables. To indicate the region within which each variable is defined, we include an additional subscript $\mathrm{k}$, which takes one of the following values: $\mathrm{n}$ (negative electrode), $\mathrm{p}$ (positive electrode), cn (negative current collector), cp (positive current collector), or s (separator). For example, the notation $\phi_{\mathrm{s}, \mathrm{n}}^{*}$ refers to the dimensional electric potential in the solid phase of the negative electrode. When stating the governing equations, we take the region in which an equation holds to be implicitly defined by the subscript of the variables. These regions, after nondimensionalization, are given by

$$
\begin{aligned}
\Omega_{\mathrm{cn}} & =\left[-L_{\mathrm{cn}}, 0\right] \times \Omega, & \Omega_{\mathrm{n}} & =\left[0, L_{\mathrm{n}}\right] \times \Omega, \quad \Omega_{\mathrm{s}}=\left[L_{\mathrm{n}}, 1-L_{\mathrm{p}}\right] \times \Omega, \\
\Omega_{\mathrm{p}} & =\left[1-L_{\mathrm{p}}, 1\right] \times \Omega, \quad \Omega_{\mathrm{cp}} & =\left[1,1+L_{\mathrm{cp}}\right] \times \Omega, &
\end{aligned}
$$

corresponding to the negative current collector, negative electrode, separator, positive electrode, and positive current collector, respectively, where $\Omega=\left[0, L_{y}\right] \times\left[0, L_{z}\right]$ is the projection of the cell onto the $(y, z)$-plane. For ease of reference we provide a glossary of the dimensionless variables, and their region of definition, in Table 3.

The through-cell coordinate $x$ has been scaled with the distance between the current collectors (i.e., with $L_{x}^{*}=L_{\mathrm{n}}^{*}+L_{\mathrm{s}}^{*}+L_{\mathrm{p}}^{*}$ shown in Figure 1 ), while the transverse coordinates $y$ and $z$ have been scaled with a typical transverse dimension $L^{*}$ (so that $L_{y}$ and $L_{z}$ are dimensionless constants of $O(1)$ ). We also introduce the notation $\partial \Omega_{\mathrm{tab}, \mathrm{k}}$ to refer to the negative and positive tabs $(\mathrm{k} \in\{\mathrm{cn}, \mathrm{cp}\}), \partial \Omega_{\mathrm{ext}, \mathrm{k}}$ to refer to the external boundaries of region $\mathrm{k} \in\{\mathrm{cn}, \mathrm{n}, \mathrm{s}, \mathrm{p}, \mathrm{cp}\}$, and $\partial \Omega_{\mathrm{k}_{1}, \mathrm{k}_{2}}$ to refer to the interface between regions $\mathrm{k}_{1}$ and $\mathrm{k}_{2}$. For instance, the notation $\partial \Omega_{\mathrm{n}, \mathrm{s}}$ refers to the interface between the negative electrode and the separator. Finally, for $\mathrm{k} \in$ $\{\mathrm{cn}, \mathrm{cp}\}$ we use $\partial \Omega_{\mathrm{tab}, \mathrm{k}, \perp}$ to denote the projection of the tabs onto the $(y, z)$-plane, and $\partial \Omega_{\mathrm{ext}, \mathrm{k}, \perp}=\partial \Omega \backslash \partial \Omega_{\mathrm{tab}, \mathrm{k}, \perp}$ to denote the nontab region of the boundary of the projection.

2.2. Governing equations. A full description of the dimensional model and its nondimensionalization is given in the supplementary material. Here, we summarize the dimensionless three-dimensional DFN model. In the following, we use the scaled gradient operator

$$
\nabla_{\delta} \equiv \frac{\partial}{\partial x} \boldsymbol{e}_{1}+\delta \frac{\partial}{\partial y} \boldsymbol{e}_{2}+\delta \frac{\partial}{\partial z} \boldsymbol{e}_{3}
$$

where $\boldsymbol{e}_{i}$ is the unit vector in the $i$ th direction, and $\delta=L_{x}^{*} / L^{*}$ is the aspect ratio of the cell (which arises because of the different scaling in the $x$ and the $y, z$ directions). A number of nondimensional parameters appear in the equations. The definitions of these, along with typical values, are listed in Table 2 in the appendix.

\footnotetext{
${ }^{1}$ In the electrolyte $c$ denotes the lithium-ion concentrations.
} 
The current in the electrodes and current collectors is given by Ohm's law, which, along with charge conservation, implies

$$
\begin{aligned}
\nabla_{\delta} \cdot \boldsymbol{i}_{\mathrm{s}, \mathrm{k}} & =0, & & \mathrm{k} \in\{\mathrm{cn}, \mathrm{cp}\}, \\
\boldsymbol{i}_{\mathrm{s}, \mathrm{k}} & =-\sigma_{\mathrm{k}} \nabla_{\delta} \phi_{\mathrm{s}, \mathrm{k}}, & & \mathrm{k} \in\{\mathrm{cn}, \mathrm{cp}\}, \\
\nabla_{\delta} \cdot \boldsymbol{i}_{\mathrm{s}, \mathrm{k}} & =-j_{\mathrm{k}}, & & \mathrm{k} \in\{\mathrm{n}, \mathrm{p}\}, \\
\boldsymbol{i}_{\mathrm{s}, \mathrm{k}} & =-\sigma_{\mathrm{k}} \nabla_{\delta} \phi_{\mathrm{s}, \mathrm{k}}, & & \mathrm{k} \in\{\mathrm{n}, \mathrm{p}\},
\end{aligned}
$$

where the interfacial current density $j_{\mathrm{k}}$ represents charge transfer between the active material and the electrolyte. The boundary conditions are

$$
\begin{aligned}
& \phi_{\mathrm{s}, \mathrm{cn}}=0, \quad \boldsymbol{x} \in \partial \Omega_{\mathrm{tab}, \mathrm{cn}}, \\
& \delta \int_{\partial \Omega_{\mathrm{tab}, \mathrm{cp}}} \boldsymbol{i}_{\mathrm{s}, \mathrm{cp}} \cdot \boldsymbol{n} \mathrm{d} A=I_{\mathrm{app}} \\
& \boldsymbol{i}_{\mathrm{s}, \mathrm{k}} \cdot \boldsymbol{n}=0, \quad \boldsymbol{x} \in \partial \Omega_{\mathrm{ext}, \mathrm{k}}, \quad \mathrm{k} \in\{\mathrm{cn}, \mathrm{n}, \mathrm{p}, \mathrm{cp}\}, \\
& \boldsymbol{i}_{\mathrm{s}, \mathrm{ck}} \cdot \boldsymbol{n}=\boldsymbol{i}_{\mathrm{s}, \mathrm{k}} \cdot \boldsymbol{n}, \quad \boldsymbol{x} \in \partial \Omega_{\mathrm{ck}, \mathrm{k}}, \quad \mathrm{k} \in\{\mathrm{n}, \mathrm{p}\}, \\
& \boldsymbol{i}_{\mathrm{s}, \mathrm{k}} \cdot \boldsymbol{n}=0, \quad \boldsymbol{x} \in \partial \Omega_{\mathrm{k}, \mathrm{s}}, \quad \mathrm{k} \in\{\mathrm{n}, \mathrm{p}\}, \\
& \phi_{\mathrm{s}, \mathrm{ck}}=\phi_{\mathrm{s}, \mathrm{k}}, \quad \boldsymbol{x} \in \partial \Omega_{\mathrm{ck}, \mathrm{k}}, \quad \mathrm{k} \in\{\mathrm{n}, \mathrm{p}\} .
\end{aligned}
$$

In addition, at the positive tab one we have the option of either (i) assuming a uniform potential over the surface of the tab, the value of which is given by satisfying the integral constraint (2.2f), or (ii) assuming a uniform current density over the surface of the tab. In our later numerical examples we make the latter assumption, so that (2.2f) can be replaced by

$$
\delta \boldsymbol{i}_{\mathrm{s}, \mathrm{cp}} \cdot \boldsymbol{n}=\frac{I_{\mathrm{app}}}{A_{\mathrm{tab}, \mathrm{cp}}}, \quad \boldsymbol{x} \in \partial \Omega_{\mathrm{tab}, \mathrm{cp}}
$$

where $A_{\mathrm{tab}, \mathrm{cp}}$ is the surface area of the positive tab. The terminal voltage is then defined as the average of the potential over the positive tab region.

Mass conservation in the active material leads to a spherical diffusion problem in the particles where the boundary flux is given by the interfacial current density

$$
\begin{array}{rlrl}
\mathcal{C}_{\mathrm{k}} \frac{\partial c_{\mathrm{s}, \mathrm{k}}}{\partial t} & =-\frac{1}{r_{\mathrm{k}}^{2}} \frac{\partial}{\partial r_{\mathrm{k}}}\left(r_{\mathrm{k}}^{2} N_{\mathrm{s}, \mathrm{k}}\right), \quad N_{\mathrm{s}, \mathrm{k}}=-D_{\mathrm{s}, \mathrm{k}}\left(c_{\mathrm{s}, \mathrm{k}}, T_{\mathrm{k}}\right) \frac{\partial c_{\mathrm{s}, \mathrm{k}}}{\partial r_{\mathrm{k}}}, & & \mathrm{k} \in\{\mathrm{n}, \mathrm{p}\}, \\
\left.N_{\mathrm{s}, \mathrm{k}}\right|_{r_{\mathrm{k}}=0} & =0, & \left.\frac{a_{\mathrm{k}} \gamma_{\mathrm{k}}}{\mathcal{C}_{\mathrm{k}}} N_{\mathrm{s}, \mathrm{k}}\right|_{r_{\mathrm{k}}=1}=j_{\mathrm{k}}, & \mathrm{k} \in\{\mathrm{n}, \mathrm{p}\}, \\
\left.c_{\mathrm{s}, \mathrm{k}}\right|_{t=0}=c_{\mathrm{s}, \mathrm{k}, 0}, & & \mathrm{k} \in\{\mathrm{n}, \mathrm{p}\},
\end{array}
$$

where $r_{\mathrm{k}}$ is the microscale coordinate indicating a radial position in the particle.

Similarly, we have charge conservation in the electrolyte in which the current is described using a modified Ohm's law:

$\nabla_{\delta} \cdot \boldsymbol{i}_{\mathrm{e}, \mathrm{k}}=\left\{\begin{array}{ll}j_{\mathrm{k}}, & \mathrm{k}=\mathrm{n}, \mathrm{p}, \\ 0, & \mathrm{k}=\mathrm{s},\end{array} \quad \mathrm{k} \in\{\mathrm{n}, \mathrm{s}, \mathrm{p}\}\right.$

$$
\mathcal{C}_{\mathrm{e}} \boldsymbol{i}_{\mathrm{e}, \mathrm{k}}=\epsilon_{\mathrm{k}}^{\mathrm{b}} \hat{\kappa}_{\mathrm{e}} \kappa_{\mathrm{e}}\left(c_{\mathrm{e}, \mathrm{k}}, T_{\mathrm{k}}\right)\left(2\left(1-t^{+}\right)\left(1+\Theta T_{\mathrm{k}}\right) \nabla_{\delta}\left(\log c_{\mathrm{e}, \mathrm{k}}\right)-\nabla_{\delta} \phi_{\mathrm{e}, \mathrm{k}}\right), \quad \mathrm{k} \in\{\mathrm{n}, \mathrm{s}, \mathrm{p}\} .
$$

Copyright $@$ by SIAM. Unauthorized reproduction of this article is prohibited. 
The current in the electrolyte satisfies the no-flux boundary conditions

$$
\begin{array}{lll}
\boldsymbol{i}_{\mathrm{e}, \mathrm{k}} \cdot \boldsymbol{n}=0, & \boldsymbol{x} \in \partial \Omega_{\mathrm{ck}, \mathrm{k}}, & \mathrm{k} \in\{\mathrm{n}, \mathrm{p}\} \\
\boldsymbol{i}_{\mathrm{e}, \mathrm{k}} \cdot \boldsymbol{n}=0, & \boldsymbol{x} \in \partial \Omega_{\mathrm{ext}, \mathrm{k}}, & \mathrm{k} \in\{\mathrm{n}, \mathrm{s}, \mathrm{p}\}
\end{array}
$$

Mass conservation in the electrolyte leads to a reaction-diffusion equation for the lithium-ion concentration:

$$
\begin{array}{rlrl}
\mathcal{C}_{\mathrm{e}} \gamma_{\mathrm{e}} \epsilon_{\mathrm{k}} \frac{\partial c_{\mathrm{e}, \mathrm{k}}}{\partial t} & =-\gamma_{\mathrm{e}} \nabla_{\delta} \cdot \boldsymbol{N}_{\mathrm{e}, \mathrm{k}}+\mathcal{C}_{\mathrm{e}} \nabla_{\delta} \cdot \boldsymbol{i}_{\mathrm{e}, \mathrm{k}}, & \mathrm{k} \in\{\mathrm{n}, \mathrm{p}\}, \\
\boldsymbol{N}_{\mathrm{e}, \mathrm{k}}=-\epsilon_{\mathrm{k}}^{\mathrm{b}} D_{\mathrm{e}}\left(c_{\mathrm{e}, \mathrm{k}}, T_{\mathrm{k}}\right) \nabla_{\delta} c_{\mathrm{e}, \mathrm{k}}+\frac{\mathcal{C}_{\mathrm{e}} t^{+}}{\gamma_{\mathrm{e}}} \boldsymbol{i}_{\mathrm{e}, \mathrm{k}}, & \mathrm{k} \in\{\mathrm{n}, \mathrm{p}\},
\end{array}
$$

which must satisfy the initial and boundary conditions

$$
\begin{array}{rlrl}
\boldsymbol{N}_{\mathrm{e}, \mathrm{k}} \cdot \boldsymbol{n} & =0, \quad \boldsymbol{x} \in \partial \Omega_{\mathrm{ext}, \mathrm{k}}, & & \mathrm{k} \in\{\mathrm{n}, \mathrm{s}, \mathrm{p}\}, \\
\boldsymbol{N}_{\mathrm{e}, \mathrm{k}} \cdot \boldsymbol{n} & =0, \quad \boldsymbol{x} \in \partial \Omega_{\mathrm{ck}, \mathrm{k}}, & \mathrm{k} \in\{\mathrm{n}, \mathrm{p}\}, \\
\boldsymbol{N}_{\mathrm{e}, \mathrm{k}} \cdot \boldsymbol{n} & =\boldsymbol{N}_{\mathrm{e}, \mathrm{s}} \cdot \boldsymbol{n}, \quad \boldsymbol{x} \in \partial \Omega_{\mathrm{k}, \mathrm{s}}, & \mathrm{k} \in\{\mathrm{n}, \mathrm{p}\}, \\
c_{\mathrm{e}, \mathrm{k}} & =c_{\mathrm{e}, \mathrm{s}}, \quad \boldsymbol{x} \in \partial \Omega_{\mathrm{k}, \mathrm{s}}, & \mathrm{k} \in\{\mathrm{n}, \mathrm{p}\}, \\
\left.c_{\mathrm{e}, \mathrm{k}}\right|_{t=0} & =c_{\mathrm{e}, 0}, & & \mathrm{k} \in\{\mathrm{n}, \mathrm{s}, \mathrm{p}\} .
\end{array}
$$

The electrochemical reactions at the surface of the solid particles are described by symmetric Butler-Volmer kinetics [26]:

$$
\begin{aligned}
j_{\mathrm{k}}=j_{0, \mathrm{k}} \sinh \left(\frac{\eta_{\mathrm{k}}}{2\left(1+\Theta T_{\mathrm{k}}\right)}\right), & \mathrm{k} \in\{\mathrm{n}, \mathrm{p}\}, \\
j_{0, \mathrm{k}}=\left.\frac{\gamma_{\mathrm{k}}}{\mathcal{C}_{\mathrm{r}, \mathrm{k}}} m_{\mathrm{k}}\left(T_{\mathrm{k}}\right) c_{\mathrm{s}, \mathrm{k}}^{1 / 2}\left(1-c_{\mathrm{s}, \mathrm{k}}\right)^{1 / 2} c_{\mathrm{e}, \mathrm{k}}^{1 / 2}\right|_{r_{\mathrm{k}}=1}, & \mathrm{k} \in\{\mathrm{n}, \mathrm{p}\}, \\
\eta_{\mathrm{k}}=\phi_{\mathrm{s}, \mathrm{k}}-\phi_{\mathrm{e}, \mathrm{k}}-\left.U_{\mathrm{k}}\left(c_{\mathrm{s}, \mathrm{k}}, c_{\mathrm{e}, \mathrm{k}}, T_{\mathrm{k}}\right)\right|_{r_{\mathrm{k}}=1}, & \mathrm{k} \in\{\mathrm{n}, \mathrm{p}\} .
\end{aligned}
$$

Finally, we have an equation for energy conservation. This accounts for Ohmic heating in both the solid and the electrolyte, as well as reversible and irreversible heating due to electrochemical reactions:

$$
\begin{array}{lll}
\delta^{2} \mathcal{C}_{\mathrm{th}} \rho_{\mathrm{k}} \frac{\partial T_{\mathrm{k}}}{\partial t}=\nabla_{\delta} \cdot\left(\lambda_{\mathrm{k}} \nabla_{\delta} T_{\mathrm{k}}\right)+\delta^{2} \mathcal{B}\left(Q_{\mathrm{ohm}, \mathrm{k}}+Q_{\mathrm{rxn}, \mathrm{k}}+Q_{\mathrm{rev}, \mathrm{k}}\right), & \mathrm{k} \in\{\mathrm{cn}, \mathrm{n}, \mathrm{s}, \mathrm{p}, \mathrm{cp}\} \\
(2.7 \mathrm{~b}) & Q_{\mathrm{Ohm}, \mathrm{k}}=-\left(\boldsymbol{i}_{\mathrm{s}, \mathrm{k}} \cdot \nabla_{\delta} \phi_{\mathrm{s}, \mathrm{k}}+\boldsymbol{i}_{\mathrm{e}, \mathrm{k}} \cdot \nabla_{\delta} \phi_{\mathrm{e}, \mathrm{k}}\right), & \mathrm{k} \in\{\mathrm{n}, \mathrm{p}\}, \\
(2.7 \mathrm{c}) & Q_{\mathrm{Ohm}, \mathrm{s}}=-\boldsymbol{i}_{\mathrm{e}, \mathrm{s}} \cdot \nabla_{\delta} \phi_{\mathrm{e}, \mathrm{s}}, & \mathrm{k} \in\{\mathrm{cn}, \mathrm{cp}\}, \\
(2.7 \mathrm{~d}) & Q_{\mathrm{Ohm}, \mathrm{k}}=-\boldsymbol{i}_{\mathrm{s}, \mathrm{k}} \cdot \nabla_{\delta} \phi_{\mathrm{s}, \mathrm{k}}, & \mathrm{k} \in\{\mathrm{n}, \mathrm{p}\}, \\
(2.7 \mathrm{e}) & Q_{\mathrm{rxn}, \mathrm{k}}=j_{\mathrm{k}} \eta_{\mathrm{k}}, & \mathrm{k} \in\{\mathrm{n}, \mathrm{p}\}, \\
(2.7 \mathrm{f}) & Q_{\mathrm{rev}, \mathrm{k}}=\left.j_{\mathrm{k}}\left(\Theta^{-1}+T_{\mathrm{k}}\right) \frac{\partial U_{\mathrm{k}}}{\partial T_{\mathrm{k}}}\right|_{T_{\mathrm{k}}=0}, &
\end{array}
$$

with $Q_{\mathrm{rxn}, \mathrm{k}}=Q_{\mathrm{rev}, \mathrm{k}}=0$ for $\mathrm{k} \in\{\mathrm{cn}, \mathrm{s}, \mathrm{cp}\}$. We assume Newton cooling on all boundaries (including the tabs), but we allow for the cooling coefficient $h$ to vary spatially. Prescribing a uniform initial temperature, the boundary and initial conditions 
are then

$$
\begin{array}{rlrlrl}
T_{\mathrm{ck}}=T_{\mathrm{k}}, & \lambda_{\mathrm{ck}} \nabla_{\delta} T_{\mathrm{ck}} \cdot \boldsymbol{n} & =\lambda_{\mathrm{k}} \nabla_{\delta} T_{\mathrm{k}} \cdot \boldsymbol{n}, & \boldsymbol{x} \in \partial \Omega_{\mathrm{ck}, \mathrm{k}}, & \mathrm{k} & \in\{\mathrm{n}, \mathrm{p}\}, \\
(2.7 \mathrm{i}) \quad T_{\mathrm{k}}=T_{\mathrm{s}}, & \lambda_{\mathrm{k}} \nabla_{\delta} T_{\mathrm{k}} \cdot \boldsymbol{n} & =\lambda_{\mathrm{s}} \nabla_{\delta} T_{\mathrm{s}} \cdot \boldsymbol{n}, & \boldsymbol{x} \in \partial \Omega_{\mathrm{k}, \mathrm{s}}, & \mathrm{k} \in\{\mathrm{n}, \mathrm{p}\}, \\
(2.7 \mathrm{j}) & \left.T_{\mathrm{k}}\right|_{t=0}=T_{0}, & & \mathrm{k} \in\{\mathrm{cn}, \mathrm{n}, \mathrm{s}, \mathrm{p}, \mathrm{cp}\} .
\end{array}
$$

Some authors have considered the effects of different cooling scenarios, such as tab cooling vs. surface cooling, on battery operation. For instance, Hunt et al. [16] conducted experiments showing that surface cooling can lead to a greater loss of capacity compared with tab cooling when discharging cells at high rates. These different cooling scenarios can be investigated by choosing particular cooling functions $h$ (for example, $h$ may be larger on the tabs).

3. Asymptotic analysis. In this section, we exploit the small aspect ratio of a typical pouch cell by considering the limit $\delta \rightarrow 0$. This is similar to the approach taken in [36]. To enable a balance of terms in the current conservation equations we rescale the transverse currents by writing

$\boldsymbol{i}_{\mathrm{s}, \mathrm{k}}=i_{\mathrm{s}, \mathrm{k}, 1} \boldsymbol{e}_{1}+\frac{\boldsymbol{i}_{\mathrm{s}, \mathrm{k}, \perp}}{\delta}, \quad \mathrm{k} \in\{\mathrm{cn}, \mathrm{n}, \mathrm{p}, \mathrm{cp}\}, \quad \boldsymbol{i}_{\mathrm{e}, \mathrm{k}}=i_{\mathrm{e}, \mathrm{k}, 1} \boldsymbol{e}_{1}+\frac{\boldsymbol{i}_{\mathrm{e}, \mathrm{k}, \perp}}{\delta}, \quad \mathrm{k} \in\{\mathrm{n}, \mathrm{s}, \mathrm{p}\}$,

where $\boldsymbol{i}_{\mathrm{s}, \mathrm{k}, \perp}$ and $\boldsymbol{i}_{\mathrm{e}, \mathrm{k}, \perp}$ are the $y-z$ components of the solid and electrolyte current, respectively. For notational convenience, we define

$$
\nabla_{\perp} \equiv \frac{\partial}{\partial y} \boldsymbol{e}_{2}+\frac{\partial}{\partial z} \boldsymbol{e}_{3}
$$

3.1. The large conductivity limit. We consider the physically relevant limit of large (dimensionless) conductivity in the current collectors. There is a distinguished limit when $\sigma_{\mathrm{k}}=\sigma_{\mathrm{k}}^{\prime} / \delta^{2}$ for $\mathrm{k} \in\{\mathrm{cn}, \mathrm{cp}\}$, where $\sigma_{\mathrm{k}}^{\prime}=\mathcal{O}(1)$ as $\delta \rightarrow 0$. Further, to retain both heat loss from the current collector surfaces (area $O(1)$ ) and heat loss from the cell edges including the tabs (area $O(\delta)$ ) at leading order we consider the limit in which $h=\delta^{2} h^{\prime}$ for $\boldsymbol{x} \in\left\{-L_{\mathrm{cn}}, 1+L_{\mathrm{cp}}\right\} \times \Omega$, and $h=\delta h^{\prime \prime}$ for the remaining external boundaries, with $h^{\prime}$ and $h^{\prime \prime}$ of $\mathcal{O}(1)$ as $\delta \rightarrow 0$. Such a scaling for the heat transfer coefficient is applicable for cooling under free convection, but $h$ may be considerably larger for forced cooling (e.g., $[17,6,5])$. All other parameters are taken to be $\mathcal{O}(1)$. We expand each variable in powers of $\delta^{2}$ as $\delta \rightarrow 0$ in the form

$$
\phi_{\mathrm{s}, \mathrm{k}}=\phi_{\mathrm{s}, \mathrm{k}}^{(0)}+\delta^{2} \phi_{\mathrm{s}, \mathrm{k}}^{(2)}+\cdots \text {. }
$$

3.1.1. Charge conservation in the solids. Using (3.1)-(3.2) the governing equations for charge transport in the current collectors, (2.2a)-(2.2b), read

$$
\begin{aligned}
\frac{\partial i_{\mathrm{s}, \mathrm{k}, 1}}{\partial x}+\nabla_{\perp} \cdot \boldsymbol{i}_{\mathrm{s}, \mathrm{k}, \perp} & =0, & \mathrm{k} \in\{\mathrm{cn}, \mathrm{cp}\} \\
\delta^{2} i_{\mathrm{s}, \mathrm{k}, 1}=-\sigma_{\mathrm{k}}^{\prime} \frac{\partial \phi_{\mathrm{s}, \mathrm{k}}}{\partial x}, & \boldsymbol{i}_{\mathrm{s}, \mathrm{k}, \perp}=-\sigma_{\mathrm{k}}^{\prime} \nabla_{\perp} \phi_{\mathrm{s}, \mathrm{k}}, & \mathrm{k} \in\{\mathrm{cn}, \mathrm{cp}\},
\end{aligned}
$$

along with the rescaled boundary conditions at the tabs,

$$
\begin{aligned}
\phi_{\mathrm{s}, \mathrm{cn}} & =0, & \boldsymbol{x} & \in \partial \Omega_{\mathrm{tab}, \mathrm{cn}}, \\
\boldsymbol{i}_{\mathrm{s}, \mathrm{cp}, \perp} \cdot \boldsymbol{n} & =\frac{I_{\mathrm{app}}}{A_{\mathrm{tab}, \mathrm{cp}}}, & \boldsymbol{x} & \in \partial \Omega_{\mathrm{tab}, \mathrm{cp}},
\end{aligned}
$$


the no-flux conditions $(2.2 \mathrm{~g})-(2.2 \mathrm{i})$, and continuity of the potential and current at the electrode/separator interfaces $x=L_{\mathrm{n}}, 1-L_{\mathrm{p}}$. After expanding in powers of $\delta^{2}$, we immediately see from $(3.4 \mathrm{~b})$ that $\phi_{\mathrm{s}, \mathrm{cn}}^{(0)}$ and $\phi_{\mathrm{s}, \mathrm{cp}}^{(0)}$ are independent of $x$, and therefore $\boldsymbol{i}_{\mathrm{s}, \mathrm{cp}, \perp}^{(0)}$ and $\boldsymbol{i}_{\mathrm{s}, \mathrm{cp}, \perp}^{(0)}$ are also independent of $x$. Then integration of the leading-order terms in (3.4a) and application of the appropriate boundary conditions give

$$
L_{\mathrm{cn}} \nabla_{\perp} \cdot i_{\mathrm{s}, \mathrm{cn}, \perp}^{(0)}=-\mathcal{I}_{\mathrm{n}}(y, z), \quad L_{\mathrm{cp}} \nabla_{\perp} \cdot \boldsymbol{i}_{\mathrm{s}, \mathrm{cp}, \perp}^{(0)}=\mathcal{I}_{\mathrm{p}}(y, z), \quad(y, z) \in \Omega,
$$

where $\mathcal{I}_{\mathrm{n}}$ and $\mathcal{I}_{\mathrm{p}}$ are the leading-order currents densities through the electrode/current collector interfaces:

$$
\mathcal{I}_{\mathrm{n}}(y, z):=\left.i_{\mathrm{s}, \mathrm{cn}, 1}^{(0)}\right|_{x=0}=\left.i_{\mathrm{s}, \mathrm{n}, 1}^{(0)}\right|_{x=0}, \quad \mathcal{I}_{\mathrm{p}}(y, z):=\left.i_{\mathrm{s}, \mathrm{cp}, 1}^{(0)}\right|_{x=1}=\left.i_{\mathrm{s}, \mathrm{p}, 1}^{(0)}\right|_{x=1} .
$$

Using (3.4b) to write (3.6) in terms of potentials gives

$$
L_{\mathrm{cn}} \sigma_{\mathrm{cn}}^{\prime} \nabla_{\perp}^{2} \phi_{\mathrm{s}, \mathrm{cn}}^{(0)}=\mathcal{I}_{\mathrm{n}}, \quad L_{\mathrm{cp}} \sigma_{\mathrm{cp}}^{\prime} \nabla_{\perp}^{2} \phi_{\mathrm{s}, \mathrm{cp}}^{(0)}=-\mathcal{I}_{\mathrm{p}}, \quad(y, z) \in \Omega,
$$

with boundary conditions

$$
\begin{aligned}
& \phi_{\mathrm{s}, \mathrm{cn}}^{(0)}=0, \quad(y, z) \in \partial \Omega_{\mathrm{tab}, \mathrm{cn}, \perp}, \\
& -\sigma_{\mathrm{cp}}^{\prime} \nabla_{\perp} \phi_{\mathrm{s}, \mathrm{cp}}^{(0)} \cdot \boldsymbol{n}=\frac{I_{\mathrm{app}}}{A_{\mathrm{tab}, \mathrm{cp}}}, \quad(y, z) \in \partial \Omega_{\mathrm{tab}, \mathrm{cp}, \perp}, \\
& \nabla_{\perp} \phi_{\mathrm{s}, \mathrm{k}}^{(0)} \cdot \boldsymbol{n}=0, \quad(y, z) \in \partial \Omega_{\mathrm{ext}, \mathrm{k}, \perp}, \quad \mathrm{k} \in\{\mathrm{cn}, \mathrm{cp}\} .
\end{aligned}
$$

In the electrodes, after using (3.1)-(3.2) the governing equations (2.2c)-(2.2d) read

$$
\begin{aligned}
\frac{\partial i_{\mathrm{s}, \mathrm{k}, 1}}{\partial x}+\nabla_{\perp} \cdot \boldsymbol{i}_{\mathrm{s}, \mathrm{k}, \perp} & =-j_{\mathrm{k}}, & \mathrm{k} \in\{\mathrm{n}, \mathrm{p}\} \\
i_{\mathrm{s}, \mathrm{k}, 1}=-\sigma_{\mathrm{k}} \frac{\partial \phi_{\mathrm{s}, \mathrm{k}}}{\partial x}, & \boldsymbol{i}_{\mathrm{s}, \mathrm{k}, \perp}=-\delta^{2} \sigma_{\mathrm{k}} \nabla_{\perp} \phi_{\mathrm{s}, \mathrm{k}}, & \mathrm{k} \in\{\mathrm{n}, \mathrm{p}\}
\end{aligned}
$$

At leading order $\boldsymbol{i}_{\mathrm{s}, \mathrm{k}, \perp}^{(0)}=0$ for $\mathrm{k} \in\{\mathrm{n}, \mathrm{p}\}$, so that

$$
\frac{\partial i_{\mathrm{s}, \mathrm{k}, 1}^{(0)}}{\partial x}=-j_{\mathrm{k}}^{(0)}, \quad i_{\mathrm{s}, \mathrm{k}, 1}^{(0)}=-\sigma_{\mathrm{k}} \frac{\partial \phi_{\mathrm{s}, \mathrm{k}}^{(0)}}{\partial x}, \quad \mathrm{k} \in\{\mathrm{n}, \mathrm{p}\}
$$

with the boundary conditions

$$
\begin{aligned}
& \left.\phi_{\mathrm{s}, \mathrm{n}}^{(0)}\right|_{x=0}=\phi_{\mathrm{s}, \mathrm{cn}}^{(0)}, \\
& \left.i_{\mathrm{s}, \mathrm{n}, 1}^{(0)}\right|_{x=L_{\mathrm{n}}}=0, \\
& \left.\phi_{\mathrm{s}, \mathrm{p}}^{(0)}\right|_{x=1}=\phi_{\mathrm{s}, \mathrm{cp}}^{(0)}, \\
& \left.i_{\mathrm{s}, \mathrm{p}, 1}^{(0)}\right|_{x=1-L_{\mathrm{p}}}=0 .
\end{aligned}
$$

3.1.2. Charge conservation in the electrolyte. A similar calculation holds for charge conservation in the electrolyte. Using (3.1)-(3.2) in (2.4b), the transverse current in the electrolyte is

$$
\begin{array}{r}
\boldsymbol{i}_{\mathrm{e}, \mathrm{k}, \perp}=\delta^{2} \epsilon_{\mathrm{k}}^{\mathrm{b}} \hat{\kappa}_{\mathrm{e}} \kappa_{\mathrm{e}}\left(c_{\mathrm{e}, \mathrm{k}}, T_{\mathrm{k}}\right)\left(-\nabla_{\perp} \phi_{\mathrm{e}, \mathrm{k}}+2\left(1-t^{+}\right)\left(1+\Theta T_{\mathrm{k}}\right) \nabla_{\perp}\left(\log c_{\mathrm{e}, \mathrm{k}}\right)\right), \\
\mathrm{k} \in\{\mathrm{n}, \mathrm{s}, \mathrm{p}\} .
\end{array}
$$

Thus, to leading order in $\delta$, we have $\boldsymbol{i}_{\mathrm{e}, \mathrm{k}, \perp}^{(0)}=0$ for $\mathrm{k} \in\{\mathrm{n}, \mathrm{s}, \mathrm{p}\}$, and the flow of current in the electrolyte is also predominantly in the $x$ direction. Then, at leading

Copyright $@$ by SIAM. Unauthorized reproduction of this article is prohibited. 
order in $\delta$, equations (2.4) give

$$
\begin{gathered}
\frac{\partial i_{\mathrm{e}, \mathrm{k}, 1}^{(0)}}{\partial x}=\left\{\begin{array}{ll}
j_{\mathrm{k}}^{(0)}, & \mathrm{k}=\mathrm{n}, \mathrm{p}, \\
0, & \mathrm{k}=\mathrm{s},
\end{array} \quad \mathrm{k} \in\{\mathrm{n}, \mathrm{s}, \mathrm{p}\}\right. \\
i_{\mathrm{e}, \mathrm{k}, 1}^{(0)}=\epsilon_{\mathrm{k}}^{\mathrm{b}} \hat{\kappa}_{\mathrm{e}} \kappa_{\mathrm{e}}\left(c_{\mathrm{e}, \mathrm{k}}^{(0)}, T_{\mathrm{k}}^{(0)}\right)\left(-\frac{\partial \phi_{\mathrm{e}, \mathrm{k}}^{(0)}}{\partial x}+2\left(1-t^{+}\right)\left(1+\Theta T_{\mathrm{k}}^{(0)}\right) \frac{\partial}{\partial x}\left(\log c_{\mathrm{e}, \mathrm{k}}^{(0)}\right)\right), \\
\mathrm{k} \in\{\mathrm{n}, \mathrm{s}, \mathrm{p}\},
\end{gathered}
$$

with boundary conditions given by $(2.4 \mathrm{c})-(2.4 \mathrm{~d})$, and continuity conditions given by

$$
\begin{aligned}
\left.i_{\mathrm{e}, \mathrm{n}, 1}^{(0)}\right|_{x=0} & =0, & \left.i_{\mathrm{e}, \mathrm{p}, 1}^{(0)}\right|_{x=1} & =0, \\
\left.\phi_{\mathrm{e}, \mathrm{n}}^{(0)}\right|_{x=L_{\mathrm{n}}} & =\left.\phi_{\mathrm{e}, \mathrm{s}}^{(0)}\right|_{x=L_{\mathrm{n}}}, & \left.i_{\mathrm{e}, \mathrm{n}, 1}^{(0)}\right|_{x=L_{\mathrm{n}}} & =\left.i_{\mathrm{e}, \mathrm{s}, 1}^{(0)}\right|_{x=L_{\mathrm{n}}}, \\
\left.\phi_{\mathrm{e}, \mathrm{s}}^{(0)}\right|_{x=1-L_{\mathrm{p}}} & =\left.\phi_{\mathrm{e}, \mathrm{p}}^{(0)}\right|_{x=1-L_{\mathrm{p}}}, & \left.i_{\mathrm{e}, \mathrm{s}, 1}^{(0)}\right|_{x=1-L_{\mathrm{p}}} & =\left.i_{\mathrm{e}, \mathrm{p}, 1}^{(0)}\right|_{x=1-L_{\mathrm{p}}} .
\end{aligned}
$$

Note that (3.10a), (3.11a) imply that $i_{\mathrm{s}, \mathrm{k}, 1}^{(0)}+i_{\mathrm{e}, \mathrm{k}, 1}^{(0)}$ is independent of $x$, so that

$$
i_{\mathrm{s}, \mathrm{k}, 1}^{(0)}+i_{\mathrm{e}, \mathrm{k}, 1}^{(0)}=\mathcal{I}_{\mathrm{k}}, \quad \mathrm{k} \in\{\mathrm{n}, \mathrm{p}\},
$$

which can be used to eliminate $i_{\mathrm{s}, \mathrm{k}, 1}^{(0)}$ in (3.10a). Note also that integrating (3.11a) in $x$ and using (3.11c)-(3.11f) gives

$$
\mathcal{I}_{\mathrm{n}}=L_{\mathrm{n}} \bar{j}_{\mathrm{n}}^{(0)}=i_{\mathrm{e}, \mathrm{s}, 1}^{(0)}=-L_{\mathrm{p}} \bar{j}_{\mathrm{p}}^{(0)}=\mathcal{I}_{\mathrm{p}}=\mathcal{I},
$$

say, where $\mathcal{I}=\mathcal{I}(y, z)$ is the through-cell current density, and

$$
\bar{j}_{\mathrm{n}}^{(0)}=\frac{1}{L_{\mathrm{n}}} \int_{0}^{L_{\mathrm{n}}} j_{\mathrm{n}}^{(0)} \mathrm{d} x, \quad \bar{j}_{\mathrm{p}}^{(0)}=\frac{1}{L_{\mathrm{p}}} \int_{1-L_{\mathrm{p}}}^{L_{\mathrm{p}}} j_{\mathrm{p}}^{(0)} \mathrm{d} x
$$

are the electrode $x$-averaged leading-order interfacial current densities.

3.1.3. Lithium conservation. For the lithium concentrations in the solid and electrolyte we find at leading order

$$
\begin{array}{rlrl}
\mathcal{C}_{\mathrm{k}} \frac{\partial c_{\mathrm{s}, \mathrm{k}}^{(0)}}{\partial t} & =-\frac{1}{r_{\mathrm{k}}^{2}} \frac{\partial}{\partial r_{\mathrm{k}}}\left(r_{\mathrm{k}}^{2} N_{\mathrm{s}, \mathrm{k}}^{(0)}\right), & \mathrm{k} \in\{\mathrm{n}, \mathrm{p}\}, \\
N_{\mathrm{s}, \mathrm{k}}^{(0)}=-D_{\mathrm{s}, \mathrm{k}}\left(c_{\mathrm{s}, \mathrm{k}}^{(0)}, T_{\mathrm{k}}^{(0)}\right) \frac{\partial c_{\mathrm{s}, \mathrm{k}}^{(0)}}{\partial r_{\mathrm{k}}}, & \mathrm{k} \in\{\mathrm{n}, \mathrm{p}\}, \\
\mathcal{C}_{\mathrm{e}} \epsilon_{\mathrm{k}} \gamma_{\mathrm{e}} \frac{\partial c_{\mathrm{e}, \mathrm{k}}^{(0)}}{\partial t}=-\gamma_{\mathrm{e}} \frac{\partial N_{\mathrm{e}, \mathrm{k}}^{(0)}}{\partial x}+\mathcal{C}_{\mathrm{e}} \frac{\partial i_{\mathrm{e}, \mathrm{k}}^{(0)}}{\partial x}, & \mathrm{k} \in\{\mathrm{n}, \mathrm{s}, \mathrm{p}\}, \\
N_{\mathrm{e}, \mathrm{k}}^{(0)}=-\epsilon_{\mathrm{k}}^{\mathrm{b}} D_{\mathrm{e}}\left(c_{\mathrm{e}, \mathrm{k}}^{(0)}, T_{\mathrm{k}}^{(0)}\right) \frac{\partial c_{\mathrm{e}, \mathrm{k}}^{(0)}}{\partial x}+\frac{\mathcal{C}_{\mathrm{e}} t^{+}}{\gamma_{\mathrm{e}}} i_{\mathrm{e}, \mathrm{k}}^{(0)}, & \mathrm{k} \in\{\mathrm{n}, \mathrm{s}, \mathrm{p}\},
\end{array}
$$

with boundary conditions

$$
\begin{array}{lrl}
\left.N_{\mathrm{s}, \mathrm{k}}^{(0)}\right|_{r_{\mathrm{k}}=0}=0, & \left.\frac{a_{\mathrm{k}} \gamma_{\mathrm{k}}}{\mathcal{C}_{\mathrm{k}}} N_{\mathrm{s}, \mathrm{k}}^{(0)}\right|_{r_{\mathrm{k}}=1} & =j_{\mathrm{k}}^{(0)}, \quad \mathrm{k} \in\{\mathrm{n}, \mathrm{p}\}, \\
\left.N_{\mathrm{e}, \mathrm{n}}^{(0)}\right|_{x=0}=0, & \left.N_{\mathrm{e}, \mathrm{p}}^{(0)}\right|_{x=1} & =0, \\
\left.c_{\mathrm{e}, \mathrm{n}}^{(0)}\right|_{x=L_{\mathrm{n}}}=\left.c_{\mathrm{e}, \mathrm{s}}^{(0)}\right|_{x=L_{\mathrm{n}}}, & \left.N_{\mathrm{e}, \mathrm{n}}^{(0)}\right|_{x=L_{\mathrm{n}}} & =\left.N_{\mathrm{e}, \mathrm{s}}^{(0)}\right|_{x=L_{\mathrm{n}}}, \\
\left.c_{\mathrm{e}, \mathrm{s}}^{(0)}\right|_{x=1-L_{\mathrm{p}}}=\left.c_{\mathrm{e}, \mathrm{p}}^{(0)}\right|_{x=1-L_{\mathrm{p}}}, & \left.N_{\mathrm{e}, \mathrm{s}}^{(0)}\right|_{x=1-L_{\mathrm{p}}} & =\left.N_{\mathrm{e}, \mathrm{p}}^{(0)}\right|_{x=1-L_{\mathrm{p}}},
\end{array}
$$

Copyright $@$ ( ) by SIAM. Unauthorized reproduction of this article is prohibited. 
and initial conditions

$$
\begin{array}{rlrl}
c_{\mathrm{s}, \mathrm{k}}^{(0)}(x, y, z, r, 0) & =c_{\mathrm{s}, \mathrm{k}, 0}, & \mathrm{k} \in\{\mathrm{n}, \mathrm{p}\}, \\
c_{\mathrm{e}, \mathrm{k}}^{(0)}(x, y, z, 0) & =1, & & \mathrm{k} \in\{\mathrm{n}, \mathrm{s}, \mathrm{p}\} .
\end{array}
$$

3.1.4. Electrochemistry. At leading order in $\delta$, the electrochemical reactions are given by

$$
\begin{array}{ll}
j_{\mathrm{k}}^{(0)}=j_{0, \mathrm{k}}^{(0)} \sinh \left(\frac{\eta_{\mathrm{k}}^{(0)}}{2\left(1+\Theta T_{\mathrm{k}}^{(0)}\right)}\right), & \mathrm{k} \in\{\mathrm{n}, \mathrm{p}\}, \\
j_{0, \mathrm{k}}^{(0)}=\left.\frac{\gamma_{\mathrm{k}}}{\mathcal{C}_{\mathrm{r}, \mathrm{k}}} m_{\mathrm{k}}\left(T_{\mathrm{k}}^{(0)}\right)\left(c_{\mathrm{s}, \mathrm{k}}^{(0)}\right)^{1 / 2}\left(1-c_{\mathrm{s}, \mathrm{k}}^{(0)}\right)^{1 / 2}\left(c_{\mathrm{e}, \mathrm{k}}^{(0)}\right)^{1 / 2}\right|_{r_{\mathrm{k}}=1}, & \mathrm{k} \in\{\mathrm{n}, \mathrm{p}\}, \\
\eta_{\mathrm{k}}^{(0)}=\phi_{\mathrm{s}, \mathrm{k}}^{(0)}-\phi_{\mathrm{e}, \mathrm{k}}^{(0)}-\left.U_{\mathrm{k}}\left(c_{\mathrm{s}, \mathrm{k}}^{(0)}, c_{\mathrm{e}, \mathrm{k}}^{(0)}, T_{\mathrm{k}}^{(0)}\right)\right|_{r_{\mathrm{k}}=1}, & \mathrm{k} \in\{\mathrm{n}, \mathrm{p}\} .
\end{array}
$$

3.1.5. Energy conservation. At leading order in (2.7) we find

$$
\frac{\partial^{2} T_{\mathrm{k}}^{(0)}}{\partial x^{2}}=0, \quad \mathrm{k} \in\{\mathrm{cn}, \mathrm{n}, \mathrm{s}, \mathrm{p}, \mathrm{cp}\}
$$

with $T_{\mathrm{k}}^{(0)}$ and $\lambda_{\mathrm{k}} \partial T_{\mathrm{k}}^{(0)} / \partial x$ continuous at $x=0,1, L_{\mathrm{n}}$, and $1-L_{\mathrm{p}}$, and

$$
\left.\frac{\partial T_{\mathrm{cn}}^{(0)}}{\partial x}\right|_{x=-L_{\mathrm{cn}}}=\left.\frac{\partial T_{\mathrm{cp}}^{(0)}}{\partial x}\right|_{x=1+L_{\mathrm{cp}}}=0
$$

giving $T^{(0)}=T^{(0)}(y, z, t)$, where we can drop the subscript $\mathrm{k}$ on the leading-order temperature since it is $x$-independent and the same across all of the cell components. At the next order, we find

$$
\begin{gathered}
\mathcal{C}_{\mathrm{th}} \rho_{\mathrm{k}} \frac{\partial T^{(0)}}{\partial t}=\lambda_{\mathrm{k}}\left(\frac{\partial^{2} T_{\mathrm{k}}^{(2)}}{\partial x^{2}}+\nabla_{\perp}^{2} T^{(0)}\right)+\mathcal{B}\left(Q_{\mathrm{Ohm}, \mathrm{k}}^{(0)}+Q_{\mathrm{rxn}, \mathrm{k}}^{(0)}+Q_{\mathrm{rev}, \mathrm{k}}^{(0)}\right), \\
\mathrm{k} \in\{\mathrm{cn}, \mathrm{n}, \mathrm{s}, \mathrm{p}, \mathrm{cp}\},
\end{gathered}
$$

where

$$
\begin{array}{ll}
Q_{\mathrm{Ohm}, \mathrm{k}}^{(0)}=\sigma_{\mathrm{k}}\left(\frac{\partial \phi_{\mathrm{s}, \mathrm{k}}^{(0)}}{\partial x}\right)^{2}-i_{\mathrm{e}, \mathrm{k}, 1}^{(0)} \frac{\partial \phi_{\mathrm{e}, \mathrm{k}}^{(0)}}{\partial x}, & \mathrm{k} \in\{\mathrm{n}, \mathrm{p}\}, \\
Q_{\mathrm{Ohm}, \mathrm{s}}^{(0)}=-i_{\mathrm{e}, \mathrm{s}, 1}^{(0)} \frac{\partial \phi_{\mathrm{e}, \mathrm{s}}^{(0)}}{\partial x}, & \mathrm{k} \in\{\mathrm{cn}, \mathrm{cp}\}, \\
Q_{\mathrm{Ohm}, \mathrm{k}}^{(0)}=\sigma_{\mathrm{k}}^{\prime}\left|\nabla_{\perp} \phi_{\mathrm{s}, \mathrm{k}}^{(0)}\right|^{2}, &
\end{array}
$$

and $Q_{\mathrm{rxn}, \mathrm{k}}^{(0)}$ and $Q_{\mathrm{rev}, \mathrm{k}}^{(0)}$ are the leading-order terms in (2.7e)-(2.7f). Integrating across the whole cell from $x=-L_{\mathrm{cn}}$ to $x=1+L_{\mathrm{cp}}$ gives

$$
\mathcal{C}_{\mathrm{th}} \sum_{\mathrm{k}}\left(\rho_{\mathrm{k}} L_{\mathrm{k}}\right) \frac{\partial T^{(0)}}{\partial t}=\sum_{\mathrm{k}}\left(\lambda_{\mathrm{k}} L_{\mathrm{k}}\right) \nabla_{\perp}^{2} T^{(0)}+\mathcal{B} \int_{-L_{\mathrm{cn}}}^{1+L_{\mathrm{cp}}} Q_{\mathrm{k}}^{(0)} \mathrm{d} x+\left[\lambda_{\mathrm{k}} \frac{\partial T_{\mathrm{k}}^{(2)}}{\partial x}\right]_{-L_{\mathrm{cn}}}^{1+L_{\mathrm{cp}}}
$$

Copyright $@$ ㅇ by SIAM. Unauthorized reproduction of this article is prohibited. 
where $Q_{\mathrm{k}}^{(0)}=Q_{\mathrm{Ohm}, \mathrm{k}}^{(0)}+Q_{\mathrm{rxn}, \mathrm{k}}^{(0)}+Q_{\mathrm{rev}, \mathrm{k}}^{(0)}$, and it is understood that the integral of $Q_{\mathrm{k}}^{(0)}$ is the sum of the integrals over each cell component. The final term of (3.18) may be evaluated through the use of the boundary condition $(2.7 \mathrm{~g})$, which gives

$$
\left.\lambda_{\mathrm{cn}} \frac{\partial T_{\mathrm{cn}}^{(2)}}{\partial x}\right|_{-L_{\mathrm{cn}}}=h_{\mathrm{cn}}^{\prime} T^{(0)},\left.\quad \lambda_{\mathrm{cp}} \frac{\partial T_{\mathrm{cp}}^{(2)}}{\partial x}\right|_{1+L_{\mathrm{cp}}}=-h_{\mathrm{cn}}^{\prime} T^{(0)}
$$

where

$$
h_{\mathrm{cn}}^{\prime}(y, z)=h^{\prime}\left(-L_{\mathrm{cn}}, y, z\right), \quad h_{\mathrm{cp}}^{\prime}(y, z)=h^{\prime}\left(1+L_{\mathrm{cp}}, y, z\right)
$$

are the heat transfer coefficients for the negative and positive current collectors, respectively. Since our choice of nondimensionalization is such that

$$
\sum_{\mathrm{k}} \rho_{\mathrm{k}} L_{\mathrm{k}}=\sum_{\mathrm{k}} \lambda_{\mathrm{k}} L_{\mathrm{k}}=\sum_{\mathrm{k}} L_{\mathrm{k}}=L_{\mathrm{cn}}+1+L_{\mathrm{cp}}=L,
$$

say, the governing equation for the leading-order temperature may be written

$$
\mathcal{C}_{\mathrm{th}} \frac{\partial T^{(0)}}{\partial t}=\nabla_{\perp}^{2} T^{(0)}+\mathcal{B} \bar{Q}^{(0)}-\frac{\left(h_{\mathrm{cn}}^{\prime}+h_{\mathrm{cp}}^{\prime}\right)}{L} T^{(0)},
$$

where

$$
\bar{Q}^{(0)}=\frac{1}{L} \int_{-L_{\mathrm{cn}}}^{1+L_{\mathrm{cp}}} Q_{\mathrm{k}}^{(0)} \mathrm{d} x
$$

is the $x$-averaged heat source term. Equation (3.20a) is subject to the initial condition

$$
T^{(0)}(y, z, 0)=T_{0}
$$

and the boundary condition

$$
-\nabla_{\perp} T^{(0)} \cdot \boldsymbol{n}=\overline{h^{\prime \prime}} T^{(0)}, \quad(y, z) \in \partial \Omega,
$$

where

$$
\overline{h^{\prime \prime}}=\frac{1}{L} \int_{-L_{\mathrm{cn}}}^{1+L_{\mathrm{cp}}} h^{\prime \prime} \mathrm{d} x
$$

is the $x$-averaged edge heat transfer coefficient.

3.1.6. Summary. To leading order the reduced model is the two-dimensional pair-potential problem

$$
L_{\mathrm{cn}} \sigma_{\mathrm{cn}}^{\prime} \nabla_{\perp}^{2} \phi_{\mathrm{s}, \mathrm{cn}}^{(0)}=\mathcal{I}, \quad L_{\mathrm{cp}} \sigma_{\mathrm{cp}}^{\prime} \nabla_{\perp}^{2} \phi_{\mathrm{s}, \mathrm{cp}}^{(0)}=-\mathcal{I} \quad \text { in } \Omega
$$

with boundary conditions

$$
\phi_{\mathrm{s}, \mathrm{cn}}^{(0)}=0 \quad \text { on } \partial \Omega_{\mathrm{tab}, \mathrm{cn}, \perp}, \quad \nabla_{\perp} \phi_{\mathrm{s}, \mathrm{cn}}^{(0)} \cdot \boldsymbol{n}=0 \quad \text { on } \partial \Omega_{\mathrm{ext}, \mathrm{cn}, \perp},
$$

$$
-\sigma_{\mathrm{cp}}^{\prime} \nabla_{\perp} \phi_{\mathrm{s}, \mathrm{cp}}^{(0)} \cdot \boldsymbol{n}=\frac{I_{\mathrm{app}}}{A_{\mathrm{tab}, \mathrm{cp}}} \text { on } \partial \Omega_{\mathrm{tab}, \mathrm{cp}, \perp}, \quad \nabla_{\perp} \phi_{\mathrm{s}, \mathrm{cp}}^{(0)} \cdot \boldsymbol{n}=0 \text { on } \partial \Omega_{\mathrm{ext}, \mathrm{cp}, \perp}
$$

where $\mathcal{I}$ is the through-cell current given (at each point $(y, z)$ ) by a one-dimensional DFN model (3.10)-(3.13), coupled to the two-dimensional thermal problem

$$
\begin{aligned}
\mathcal{C}_{\mathrm{th}} \frac{\partial T^{(0)}}{\partial t} & =\nabla_{\perp}^{2} T^{(0)}+\mathcal{B} \bar{Q}^{(0)}-\frac{\left(h_{\mathrm{cn}}^{\prime}+h_{\mathrm{cp}}^{\prime}\right)}{L} T^{(0)} \quad \text { in } \Omega, \\
-\nabla_{\perp} T^{(0)} \cdot \boldsymbol{n} & =\overline{h^{\prime \prime}} T^{(0)} \quad \text { on } \partial \Omega
\end{aligned}
$$

Copyright (c) by SIAM. Unauthorized reproduction of this article is prohibited. 
with initial condition $T^{(0)}=T_{0}$, where the heat source is

$$
\bar{Q}^{(0)}=\frac{1}{L} \int_{0}^{1} Q_{\mathrm{DFN}}^{(0)} \mathrm{d} x+\frac{L_{\mathrm{cn}}}{L} \sigma_{\mathrm{cn}}^{\prime}\left|\nabla_{\perp} \phi_{\mathrm{s}, \mathrm{cn}}^{(0)}\right|^{2}+\frac{L_{\mathrm{cp}}}{L} \sigma_{\mathrm{cp}}^{\prime}\left|\nabla_{\perp} \phi_{\mathrm{s}, \mathrm{cp}}^{(0)}\right|^{2}
$$

where $Q_{\mathrm{DFN}}^{(0)}=Q_{\mathrm{Ohm}, \mathrm{k}}^{(0)}+Q_{\mathrm{rxn}, \mathrm{k}}^{(0)}+Q_{\mathrm{rev}, \mathrm{k}}^{(0)}(\mathrm{k} \in\{\mathrm{n}, \mathrm{s}, \mathrm{p}\})$ is the heat source in the one-dimensional DFN model. The dimensional version of these equations is given in section SM9.1 of the supplementary material.

3.2. The very large conductivity limit. The model derived in section 3.1 is the distinguished limit in which the resistance to current traveling down the current collector is comparable to that to current traveling through the cell. In applications, in order to ensure the whole cell is used uniformly, the current collectors are designed to be thick enough that the potential on them is approximately uniform. In this section we analyze this situation by considering the sublimit $\sigma_{\mathrm{k}}^{\prime} \gg 1$.

In section 3.1 we also took the edge cooling coefficient to be asymptotically larger than the surface cooling coefficient, so that both effects appeared in the leading-order heat balance. In this section we weaken the effect of edge cooling by considering the sublimit $h^{\prime \prime} \ll 1$. We also suppose that the surface cooling coefficients $h_{\mathrm{k}}^{\prime}$ do not vary spatially, so that the temperature is also approximately uniform.

We will see that with these approximations the model simplifies considerably. For ease of exposition we quantify the limits by introducing a single small parameter $\varepsilon$ such that $\sigma_{\mathrm{k}}^{\prime}=\sigma_{\mathrm{k}}^{\prime \prime} / \varepsilon, h^{\prime \prime}=h^{\prime \prime \prime} \varepsilon$ with $\sigma_{\mathrm{k}}^{\prime \prime}, h^{\prime \prime \prime}=\mathcal{O}(1)$ as $\varepsilon \rightarrow 0$. We now expand the leading-order term of section 3.1 in each variable in powers of $\varepsilon$ as

$$
\phi_{\mathrm{s}, \mathrm{k}}^{(0)}=\phi_{\mathrm{s}, \mathrm{k}}^{(00)}+\varepsilon \phi_{\mathrm{s}, \mathrm{k}}^{(01)}+\cdots,
$$

as $\varepsilon \rightarrow 0$. We will retain both the leading term and the first correction in this expansion in $\varepsilon$, while neglecting the first correction in the expansion in $\delta^{2}$; thus our results are asymptotically accurate, providing $\delta^{2} \ll \varepsilon$. After rewriting $\sigma_{\mathrm{k}}^{\prime}$ and $h^{\prime \prime}$, equations (3.21) become

$$
\begin{array}{ccc}
L_{\mathrm{cn}} \sigma_{\mathrm{cn}}^{\prime \prime} \nabla_{\perp}^{2} \phi_{\mathrm{s}, \mathrm{cn}}^{(0)}=\varepsilon \mathcal{I}, & L_{\mathrm{cp}} \sigma_{\mathrm{cp}}^{\prime \prime} \nabla_{\perp}^{2} \phi_{\mathrm{s}, \mathrm{cp}}^{(0)}=-\varepsilon \mathcal{I} \quad \text { in } \Omega, \\
\phi_{\mathrm{s}, \mathrm{cn}}^{(0)}=0 \quad \text { on } \partial \Omega_{\mathrm{tab}, \mathrm{cn}, \perp}, & \nabla_{\perp} \phi_{\mathrm{s}, \mathrm{cn}}^{(0)} \cdot \boldsymbol{n}=0 \quad \text { on } \partial \Omega_{\mathrm{ext}, \mathrm{cn}, \perp},
\end{array}
$$

with initial condition $T^{(0)}=T_{0}$. It is useful to write down also a global current conservation equation by integrating the second equation in (3.23a) over $\Omega$ and using (3.23c) to give

$$
I_{\text {app }}=\int_{\Omega} \mathcal{I} \mathrm{d} y \mathrm{~d} z
$$

Copyright $@$ by SIAM. Unauthorized reproduction of this article is prohibited. 
3.2.1. Leading-order problem. At leading order in $\varepsilon$ we find the potentials are uniform as expected, with

$$
\phi_{\mathrm{s}, \mathrm{cn}}^{(00)}=0, \quad \phi_{\mathrm{s}, \mathrm{cp}}^{(00)}=V^{(00)}(t),
$$

where $V^{(00)}(t)$ is the (unknown) leading-order terminal voltage. Since (3.23e) gives

$$
-\nabla_{\perp} T^{(00)} \cdot \boldsymbol{n}=0 \quad \text { on } \partial \Omega
$$

the leading-order temperature $T^{(00)}$ will be spatially uniform if the heat source $\bar{Q}^{(00)}$ is spatially uniform. On the other hand, if $T^{(00)}$ is spatially uniform, then at each point $(y, z)$ the one-dimensional DFN model (3.11)-(3.13) sees the same temperature $T^{(00)}$ and potential difference $V(t)$, so that (providing the initial condition is independent of $y$ and $z$ ) the solution to each of these models is independent of $y$ and $z$, and the through-cell current $\mathcal{I}^{(00)}$ and heating $\bar{Q}^{(00)}$ are uniform. Thus a single onedimensional DFN problem suffices to determine $V^{(00)}$ as a functional of $\mathcal{I}^{(00)}$ and $T^{(00)}$. Let us write this output of the DFN model as

$$
\phi_{\mathrm{s}, \mathrm{cp}}-\phi_{\mathrm{s}, \mathrm{cn}}=V_{\mathrm{DFN}}(\mathcal{I}, T),
$$

so that $V^{(00)}=V_{\mathrm{DFN}}\left(\mathcal{I}^{(00)}, T^{(00)}\right)$. The current $\mathcal{I}^{(00)}$ is given by $(3.23 \mathrm{f})$ as

$$
\mathcal{I}^{(00)}=\frac{I_{\mathrm{app}}}{L_{y} L_{z}},
$$

while the leading-order temperature is determined from the ordinary differential equation

$$
\mathcal{C}_{\mathrm{th}} \frac{\mathrm{d} T^{(00)}}{\mathrm{d} t}=\mathcal{B} \bar{Q}_{\mathrm{DFN}}\left(\mathcal{I}^{(00)}, T^{(00)}\right)-\frac{\left(h_{\mathrm{cn}}^{\prime}+h_{\mathrm{cp}}^{\prime}\right)}{L} T^{(00)}
$$

with initial condition $T^{(00)}(0)=T_{0}$, where

$$
\bar{Q}_{\mathrm{DFN}}(\mathcal{I}, T)=\frac{1}{L} \int_{0}^{1} Q_{\mathrm{DFN}}^{(0)} \mathrm{d} x
$$

is the $x$-averaged heat source in the one-dimensional DFN model, which, like $V_{\mathrm{DFN}}$, is a functional of the temperature $T$ and current $\mathcal{I}$.

3.2.2. First-order correction. The first-order corrections to the current collector potentials satisfy

$$
\begin{aligned}
& L_{\mathrm{cn}} \sigma_{\mathrm{cn}}^{\prime \prime} \nabla_{\perp}^{2} \phi_{\mathrm{s}, \mathrm{cn}}^{(01)}=\frac{I_{\mathrm{app}}}{L_{y} L_{z}}, \quad L_{\mathrm{cp}} \sigma_{\mathrm{cp}}^{\prime \prime} \nabla_{\perp}^{2} \phi_{\mathrm{s}, \mathrm{cp}}^{(01)}=-\frac{I_{\mathrm{app}}}{L_{y} L_{z}} \quad \text { in } \Omega, \\
& \phi_{\mathrm{s}, \mathrm{cn}}^{(01)}=0 \quad \text { on } \partial \Omega_{\mathrm{tab}, \mathrm{cn}, \perp}, \quad \nabla_{\perp} \phi_{\mathrm{s}, \mathrm{cn}}^{(01)} \cdot \boldsymbol{n}=0 \quad \text { on } \partial \Omega_{\mathrm{ext}, \mathrm{cn}, \perp},
\end{aligned}
$$

$(3.29 \mathrm{c})-\sigma_{\mathrm{cp}}^{\prime \prime} \nabla_{\perp} \phi_{\mathrm{s}, \mathrm{cp}}^{(01)} \cdot \boldsymbol{n}=\frac{I_{\mathrm{app}}}{A_{\mathrm{tab}, \mathrm{cp}}}$ on $\partial \Omega_{\mathrm{tab}, \mathrm{cp}, \perp}, \quad \nabla_{\perp} \phi_{\mathrm{s}, \mathrm{cp}}^{(01)} \cdot \boldsymbol{n}=0$ on $\partial \Omega_{\mathrm{ext}, \mathrm{cp}, \perp} \cdot$

We note that $\phi_{\mathrm{s}, \mathrm{cp}}^{(01)}$ is only determined up to a function of time, which is fixed by solving the through-cell DFN problem at $\mathcal{O}(\varepsilon)$. However, we will see that we can 
evaluate this term without solving multiple DFN models parameterized by $y$ and $z$. We use (3.25) to write

$$
\phi_{\mathrm{s}, \mathrm{cp}}^{(01)}-\phi_{\mathrm{s}, \mathrm{cn}}^{(01)}=\frac{\delta V_{\mathrm{DFN}}}{\delta \mathcal{I}} \mathcal{I}^{(01)}+\frac{\delta V_{\mathrm{DFN}}}{\delta T} T^{(01)},
$$

where the functional derivatives are evaluated at $\left(\mathcal{I}^{(00)}, T^{(00)}\right)$ and are therefore independent of $y$ and $z$. Integrating over $\Omega$ gives

$$
\left\langle\phi_{\mathrm{s}, \mathrm{cp}}^{(01)}\right\rangle-\left\langle\phi_{\mathrm{s}, \mathrm{cn}}^{(01)}\right\rangle=\frac{\delta V_{\mathrm{DFN}}}{\delta \mathcal{I}}\left\langle\mathcal{I}^{(01)}\right\rangle+\frac{\delta V_{\mathrm{DFN}}}{\delta T}\left\langle T^{(01)}\right\rangle
$$

where

$$
\langle\cdot\rangle=\frac{1}{L_{y} L_{z}} \int_{\Omega} \cdot \mathrm{d} y \mathrm{~d} z .
$$

But (3.23f) gives

$$
\left\langle\mathcal{I}^{(01)}\right\rangle=0
$$

so the only contribution from the DFN at $O(\varepsilon)$ is from the temperature perturbation.

Recalling that the terminal voltage is the average of the potential over the positive tab,

$$
V^{(01)}=\frac{L_{\mathrm{cp}}}{A_{\mathrm{tab}, \mathrm{cp}}} \int_{\partial \Omega_{\mathrm{tab}, \mathrm{cp}, \perp}} \phi_{\mathrm{s}, \mathrm{cp}}^{(01)} \mathrm{d} s
$$

and (3.29a) is enough to determine $\left\langle\phi_{\mathrm{s}, \mathrm{cn}}^{(01)}\right\rangle$ and $V^{(01)}-\left\langle\phi_{\mathrm{s}, \mathrm{cp}}^{(01)}\right\rangle$, which can be interpreted as the potential drops across the negative and positive current collectors, respectively. Since these are proportional to $I_{\text {app }}$ (which may be time dependent) they can be most easily formulated in terms of current collector resistances by writing

$$
\left\langle\phi_{\mathrm{s}, \mathrm{cn}}^{(01)}\right\rangle=-R_{\mathrm{cn}} I_{\mathrm{app}}, \quad V^{(01)}-\left\langle\phi_{\mathrm{s}, \mathrm{cp}}^{(01)}\right\rangle=-R_{\mathrm{cp}} I_{\mathrm{app}}
$$

where

$$
R_{\mathrm{cn}}=\frac{\left\langle f_{\mathrm{n}}\right\rangle}{L_{y} L_{z} L_{\mathrm{cn}} \sigma_{\mathrm{cn}}^{\prime \prime}}, \quad R_{\mathrm{cp}}=\frac{1}{L_{y} L_{z} \sigma_{\mathrm{cp}}^{\prime \prime} A_{\mathrm{tab}, \mathrm{cp}}} \int_{\partial \Omega_{\mathrm{tab}, \mathrm{cp}, \perp}} f_{\mathrm{p}} \mathrm{d} s
$$

with

$$
\nabla_{\perp} f_{\mathrm{p}} \cdot \boldsymbol{n}=\frac{L_{y} L_{z} L_{\mathrm{cp}}}{A_{\mathrm{tab}, \mathrm{cp}}} \text { on } \partial \Omega_{\mathrm{tab}, \mathrm{cp}, \perp}, \quad \nabla_{\perp} f_{\mathrm{p}} \cdot \boldsymbol{n}=0 \quad \text { on } \partial \Omega_{\mathrm{ext}, \mathrm{cp}, \perp}, \quad\left\langle f_{\mathrm{p}}\right\rangle=0 .
$$

Combining (3.31) with (3.30) gives the perturbation to the terminal voltage as

$$
V^{(01)}=\frac{\delta V_{\mathrm{DFN}}}{\delta T}\left\langle T^{(01)}\right\rangle-R_{\mathrm{cp}} I_{\mathrm{app}}-R_{\mathrm{cn}} I_{\mathrm{app}}
$$

At next order in (3.23d)-(3.23e) we find

$$
\begin{aligned}
\mathcal{C}_{\mathrm{th}} \frac{\partial T^{(01)}}{\partial t} & =\nabla_{\perp}^{2} T^{(01)}+\mathcal{B} \frac{\delta \bar{Q}_{\mathrm{DFN}}}{\delta T} T^{(01)}-\frac{\left(h_{\mathrm{cn}}^{\prime}+h_{\mathrm{cp}}^{\prime}\right)}{L} T^{(01)} \\
+ & \frac{\mathcal{B} L_{\mathrm{cn}} \sigma_{\mathrm{cn}}^{\prime \prime}}{L}\left|\nabla_{\perp} \phi_{\mathrm{s}, \mathrm{cn}}^{(01)}\right|^{2}+\frac{\mathcal{B} L_{\mathrm{cp}} \sigma_{\mathrm{cp}}^{\prime \prime}}{L}\left|\nabla_{\perp} \phi_{\mathrm{s}, \mathrm{cp}}^{(01)}\right|^{2} \quad \text { in } \Omega, \\
-\nabla_{\perp} T^{(01)} \cdot \boldsymbol{n} & =\overline{h^{\prime \prime \prime}} T^{(00)} \quad \text { on } \partial \Omega,
\end{aligned}
$$

Copyright $@$ by SIAM. Unauthorized reproduction of this article is prohibited. 
where the functional derivative is evaluated at $T^{(00)}$. Integrating over $y$ and $z$ gives

$$
\begin{aligned}
\mathcal{C}_{\mathrm{th}} \frac{\partial\left\langle T^{(01)}\right\rangle}{\partial t}=\mathcal{B} \frac{\delta \bar{Q}_{\mathrm{DFN}}}{\delta T}\left\langle T^{(01)}\right\rangle-\frac{\left(h_{\mathrm{cn}}^{\prime}+h_{\mathrm{cp}}^{\prime}\right)}{L}\left\langle T^{(01)}\right\rangle & \\
& -\frac{T^{(00)}}{L_{y} L_{z}} \int_{\partial \Omega} \overline{h^{\prime \prime \prime}} \mathrm{d} s+H_{\mathrm{cn}} I_{\mathrm{app}}^{2}+H_{\mathrm{cp}} I_{\mathrm{app}}^{2} \quad \text { in } \Omega,
\end{aligned}
$$

where the coefficients related to Ohmic heating in the current collectors are

$$
H_{\mathrm{cn}}=\frac{\mathcal{B} L_{\mathrm{cn}}}{L\left(L_{y} L_{z} L_{\mathrm{cn}}\right)^{2} \sigma_{\mathrm{cn}}^{\prime \prime}}\left\langle\left|\nabla_{\perp} f_{\mathrm{n}}\right|^{2}\right\rangle, \quad H_{\mathrm{cp}}=\frac{\mathcal{B} L_{\mathrm{cp}}}{L\left(L_{y} L_{z} L_{\mathrm{cp}}\right)^{2} \sigma_{\mathrm{cp}}^{\prime \prime}}\left\langle\left|\nabla_{\perp} f_{\mathrm{p}}\right|^{2}\right\rangle
$$

In principle (3.35) allows the correction to the average temperature to be determined, whence (3.34) gives the correction to the terminal voltage. Rather than evaluating $\delta V_{\mathrm{DFN}} / \delta T$ and $\delta \bar{Q}_{\mathrm{DFN}} / \delta T$, the most convenient way to capture the perturbation is to note that

$$
\begin{aligned}
V_{\mathrm{DFN}}\left(\mathcal{I}^{(00)}, T^{(00)}+\varepsilon\left\langle T^{(01)}\right\rangle\right)= & V_{\mathrm{DFN}}\left(\mathcal{I}^{(00)}, T^{(00)}\right) \\
& +\varepsilon \frac{\delta V_{\mathrm{DFN}}}{\delta T}\left(\mathcal{I}^{(00)}, T^{(00)}\right)\left\langle T^{(01)}\right\rangle+O\left(\varepsilon^{2}\right),
\end{aligned}
$$

so that

$$
V^{(00)}+\varepsilon V^{(01)}=V_{\mathrm{DFN}}\left(\mathcal{I}^{(00)}, T^{(00)}+\varepsilon\left\langle T^{(01)}\right\rangle\right)-\varepsilon R_{\mathrm{cp}} I_{\mathrm{app}}-\varepsilon R_{\mathrm{cn}} I_{\mathrm{app}}+O\left(\varepsilon^{2}\right) .
$$

Thus we may solve a single one-dimensional DFN using the $y, z$-averaged temperature, and the error will be $O\left(\varepsilon^{2}\right)$.

3.2.3. Summary. Writing $\langle T\rangle=T^{(00)}+\varepsilon\left\langle T^{(01)}\right\rangle$ gives

$$
\begin{gathered}
V=V_{\mathrm{DFN}}\left(\mathcal{I}^{(00)},\langle T\rangle\right)-\varepsilon R_{\mathrm{cp}} I_{\mathrm{app}}-\varepsilon R_{\mathrm{cn}} I_{\mathrm{app}}+O\left(\varepsilon^{2}, \delta^{2}\right) \\
\mathcal{C}_{\mathrm{th}} \frac{\partial\langle T\rangle}{\partial t}=\mathcal{B} \bar{Q}_{\mathrm{DFN}}\left(\mathcal{I}^{(00)},\langle T\rangle\right)-\frac{\left(h_{\mathrm{cn}}^{\prime}+h_{\mathrm{cp}}^{\prime}\right)}{L}\langle T\rangle-\frac{\varepsilon\langle T\rangle}{L_{y} L_{z}} \int_{\partial \Omega} \overline{h^{\prime \prime \prime}} \mathrm{d} s \\
+\varepsilon H_{\mathrm{cn}} I_{\mathrm{app}}^{2}+\varepsilon H_{\mathrm{cp}} I_{\mathrm{app}}^{2}+O\left(\varepsilon^{2}, \delta^{2}\right) \quad \text { in } \Omega .
\end{gathered}
$$

After solving this single one-dimensional model, the potential distribution in the current collectors is

$$
\phi_{\mathrm{s}, \mathrm{cn}}=-\frac{\varepsilon \mathcal{I}^{(00)}}{L_{\mathrm{cn}} \sigma_{\mathrm{cn}}^{\prime \prime}} f_{\mathrm{n}}+O\left(\varepsilon^{2}, \delta^{2}\right), \quad \phi_{\mathrm{s}, \mathrm{cp}}=V+\frac{\varepsilon \mathcal{I}^{(00)}}{L_{\mathrm{cp}} \sigma_{\mathrm{cp}}^{\prime \prime}} f_{\mathrm{p}}+O\left(\varepsilon^{2}, \delta^{2}\right) .
$$

Recall that in this limit the leading-order current is $\mathcal{I}^{(00)}=I_{\text {app }} /\left(L_{y} L_{z}\right)$. The dimensional version of these equations is given in section SM9.1.1 of the supplementary material.

3.2.4. An ad-hoc model for the temperature distribution. The reduced model (3.37) gives the spatial variation of the potential in the current collectors, but only the average cell temperature. An approach sometimes used in the literature is to retain the spatial derivatives in the energy balance equation, but use heat source terms from the averaged one-dimensional electrochemical model (see, e.g., [15]). Such an approach corresponds to replacing $\bar{Q}_{\mathrm{DFN}}\left(\mathcal{I}^{(00)}, T\right)$ with $\bar{Q}_{\mathrm{DFN}}\left(\mathcal{I}^{(00)},\langle T\rangle\right)$ and replaces 
(3.37b) with

$$
\begin{aligned}
& \mathcal{C}_{\mathrm{th}} \frac{\partial T}{\partial t}=\nabla_{\perp}^{2} T+\mathcal{B} \bar{Q}_{\mathrm{DFN}}\left(\mathcal{I}^{(00)},\langle T\rangle\right)-\frac{\left(h_{\mathrm{cn}}^{\prime}+h_{\mathrm{cp}}^{\prime}\right)}{L} T \\
&+ \frac{\mathcal{B} L_{\mathrm{cn}} \sigma_{\mathrm{cn}}^{\prime \prime}}{\varepsilon L}\left|\nabla_{\perp} \phi_{\mathrm{s}, \mathrm{cn}}\right|^{2}+\frac{\mathcal{B} L_{\mathrm{cp}} \sigma_{\mathrm{cp}}^{\prime \prime}}{\varepsilon L}\left|\nabla_{\perp} \phi_{\mathrm{s}, \mathrm{cp}}\right|^{2} \quad \text { in } \Omega, \\
&-\nabla_{\perp} T \cdot \boldsymbol{n}=\varepsilon \overline{h^{\prime \prime \prime} T} \quad \text { on } \partial \Omega .
\end{aligned}
$$

This model captures the variation due to Ohmic heating in the current collectors and cooling at the boundaries, but neglects the spatial variation of the heat source within the cell.

4. Comparison of models. In this section, we provide a numerical comparison of the full model with the reduced models (3.21) and (3.37). For ease of exposition we focus on the case in which all variables are uniform in $y$, so that the full model is twodimensional, and the reduced model (3.21) has a one-dimensional current collector (in the $z$ direction), at each point of which we solve a one-dimensional DFN model (we refer to this as a $1+1 \mathrm{D}$ model, though since the DFN is already a pseudo-twodimensional model, perhaps it is more properly a $1+1+1 \mathrm{D}$ model). We refer to the very high conductivity limit model (3.37) as the DFNCC model, to indicate that it involves a single (averaged) DFN model with an additional (uncoupled) problem for the distribution of potential in the current collectors (from which the resistance and heat source can be calculated).

Numerical simulations of the full model were performed using the commercial software COMSOL [7], while the reduced models were implemented in the opensource battery modeling package PyBaMM (Python Battery Mathematical Modelling) [37]. All simulations were performed on a desktop computer (i5 processor, $2.1 \mathrm{GHz}$ ) with $16 \mathrm{~Gb}$ of RAM. The model equations in COMSOL are discretized in space using the finite element method (FEM), while in PyBaMM the equations are discretized using the finite volume method (FVM). In all simulations the solid phase diffusion is also treated by discretizing the partial differential equation (2.3) in space, using FEM in COMSOL and FVM in PyBaMM. Both solvers use an adaptive, variableorder backward differentiation formula for the time integration, with both relative and absolute tolerances set to $10^{-6}$. Since we aim to compare the full and reduced models and not the merits of any particular numerical approach, we provide a comparison of the solutions of the standard one-dimensional DFN model produced by both COMSOL and PyBaMM in the supplementary material. While this does not fully quantify differences introduced by employing two different numerical solution methods, it does provide context for our comparisons that follow.

Typical dimensional parameter values for a battery comprising a carbon negative current collector, graphite negative electrode, $\mathrm{LiPF}_{6}$ in EC:DMC electrolyte, LCO positive electrode, and aluminum positive current collector are given in Table SM1 (taken from [25]). These translate into the nondimensional parameters given in Table 2. From there we see that

$$
h \approx 3.8 \times 10^{-5}, \quad \delta \approx 1.6 \times 10^{-3} .
$$

The dimensionless conductivities $\sigma_{\mathrm{cn}}$ and $\sigma_{\mathrm{cp}}$ depend on the charge/discharge rate (the so-called C-rate). ${ }^{2}$ To give an idea of the typical asymptotic regime batteries

\footnotetext{
${ }^{2}$ It is standard practice in the field to measure C-rates in multiples of the rate at which the battery would charge/discharge in 1 hour, known as $1 \mathrm{C}$. Thus, for example, at a discharge rate $2 \mathrm{C}$ the battery would discharge in 30 minutes.
} 

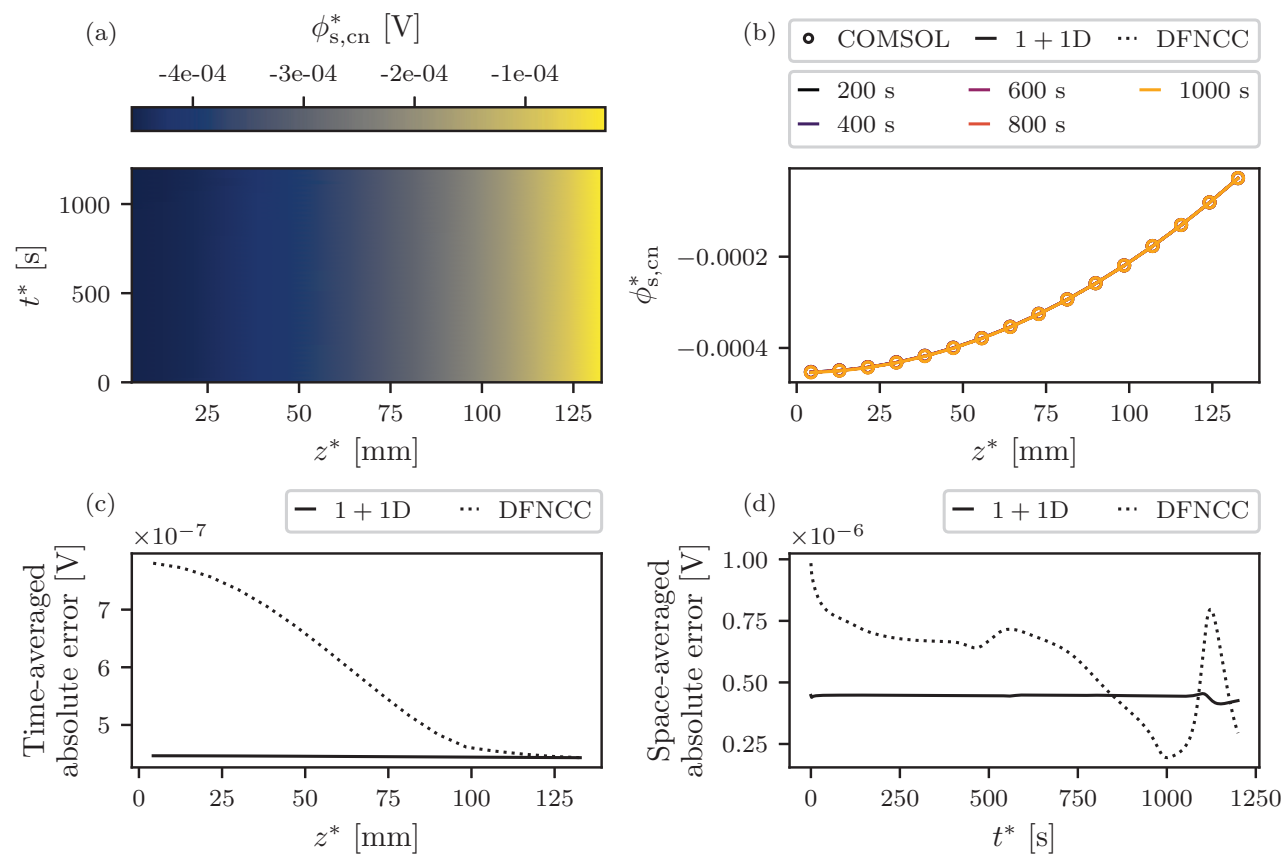

FIG. 2. Potential in the negative current collector. (a) The COMSOL solution; (b) comparison with the reduced models at various times during discharge; (c) time-averaged absolute errors; (d) $z$-averaged absolute errors.

operate in, at a C-rate of 3 we find that

$$
\sigma_{\mathrm{cn}} \approx 9.5 \times 10^{7}, \quad \sigma_{\mathrm{cp}} \approx 5.6 \times 10^{7} .
$$

We compare the results of the two-dimensional DFN model with the 1+1D DFN and DFNCC models for a $3 \mathrm{C}$ constant current discharge, with both positive and negative tabs placed at the top of the cell (i.e., at $z=L_{z}$ ). In Figures 2, 3, 4, and 5 we present comparisons for the potential in the negative current collector, the potential in the positive current collector, the through-cell current density, and the $x$-averaged temperature, respectively. Solutions from the full model are shown as a function of space in time in panel (a), with snapshots at a series of times throughout the discharge shown in panel (b). The time- and space-averaged absolute errors ${ }^{3}$ are shown in panels (c) and (d), respectively.

We see in Figures 2 and 3 that the electrical conductivity of the current collectors is sufficiently high that the potentials remain fairly uniform in space, and both the $1+1 \mathrm{D}$ DFN and DFNCC models are able to accurately capture the potential distribution in the current collectors. The error is of a similar size to that between the numerical solutions of the one-dimensional DFN obtained using COMSOL and PyBaMM (section SM8), so that little additional error has been introduced as a result of the asymptotic reduction.

\footnotetext{
${ }^{3}$ By "error" we mean the difference between the numerical solution of the reduced model in PyBaMM and the COMSOL solution of the full model.
} 

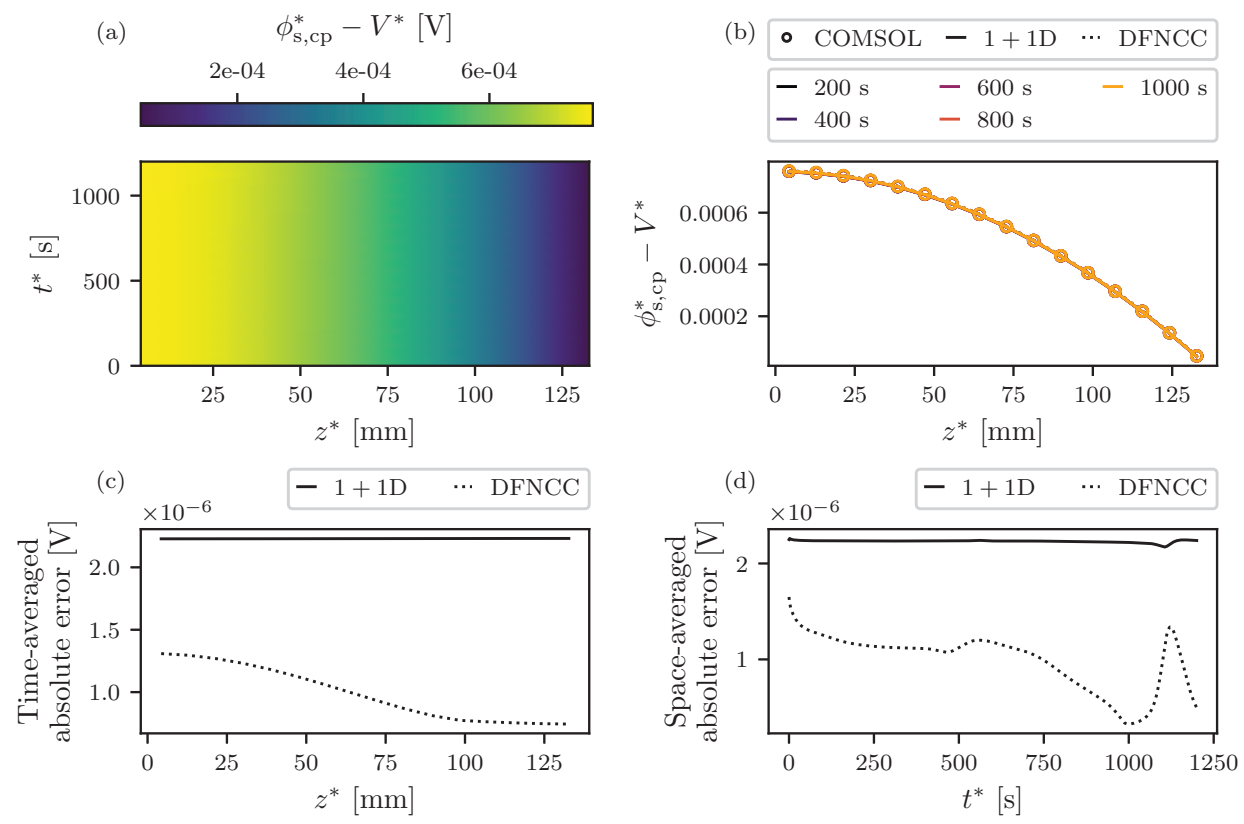

FIG. 3. Potential in the positive current collector (with the terminal voltage subtracted off). (a) The COMSOL solution; (b) comparison with the reduced models at various times during discharge; (c) time-averaged absolute errors; (d) z-averaged absolute errors.

In Figure 4(a) we see that positioning both tabs at the top of the cell means that for most of the simulation the current preferentially travels through the upper part of the cell. Eventually, as the cell continues to discharge, this part becomes more (de)lithiated until the resultant local increase in through-cell resistance is sufficient for it to become preferential for the current to travel further along the current collectors and through the lower part of the cell (as seen in the final time shown in Figure 4(b)). This behavior is well captured by the $1+1 \mathrm{D}$ model, with space-averaged absolute errors in the through-cell current on the order of $10^{-3} \mathrm{~A} \mathrm{~m}^{-2}$ for most of the discharge, as displayed in Figure 4(d). The largest error is found towards the end of the discharge where the open circuit voltage becomes highly nonlinear. ${ }^{4}$ In the DFNCC formulation the through-cell current density is assumed uniform, so the greatest error is found at the ends of the current collectors where the current density deviates most from its average.

For the parameters given in Table SM1, we find that the temperature exhibits a relatively weak variation along the length of the current collectors, as shown in Figure 5. The 1+1D model captures the temperature distribution well.

Since the temperature rise is moderate (and the variation of temperature in space is small), the uniform temperature predicted by the DFNCC model gives a good estimate of the temperature in the full model.

In Table 1, we give the normalized root mean square (RMS) error in the current collector potentials, through-cell current, temperature, and voltage obtained by solving the model in PyBaMM as the mesh is refined. The RMS error was computed with respect to the solution obtained using COMSOL's "fine" mesh(450 elements in

\footnotetext{
${ }^{4}$ However, this is also where the greatest discrepancy in the solution between COMSOL and $\mathrm{PyBaMM}$ in one dimension is found (see the $1 \mathrm{C}$ result in Figure SM1).
} 

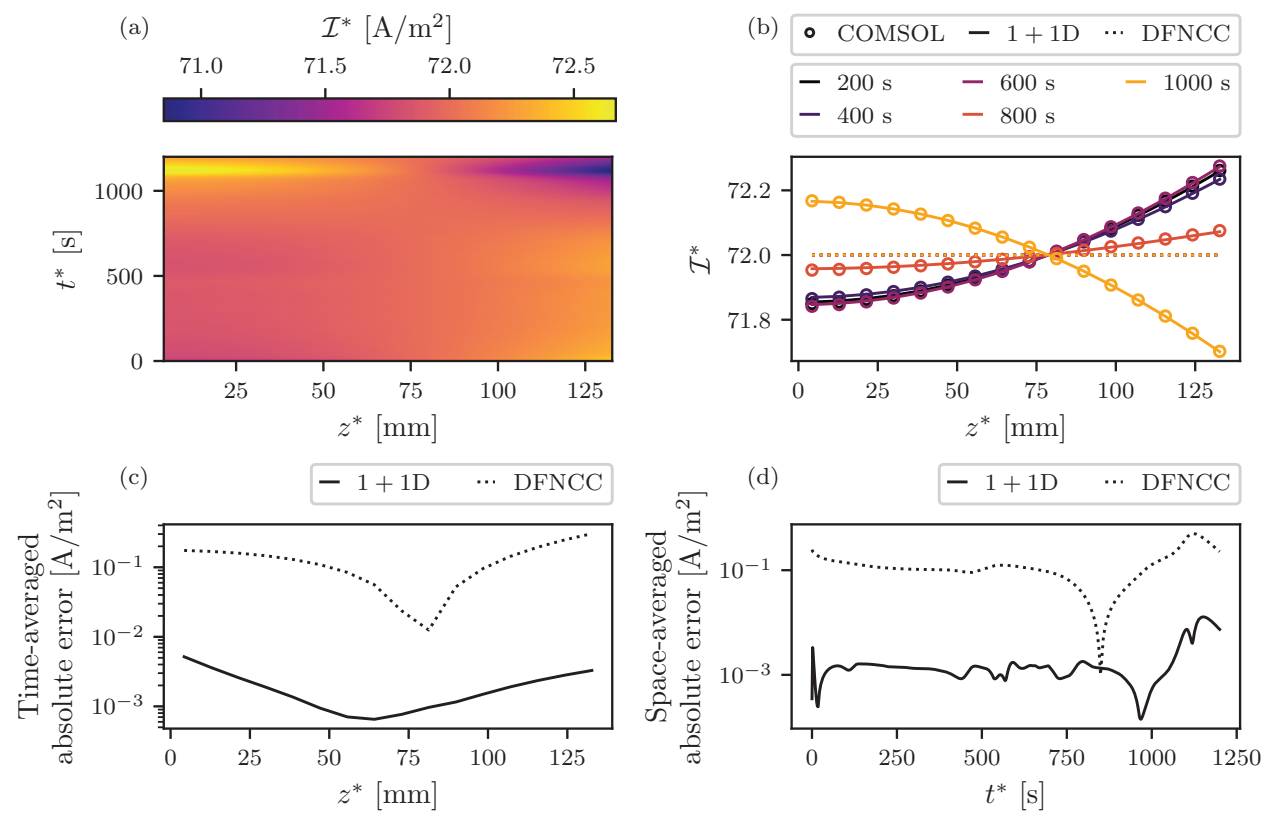

FIG. 4. Through-cell current density. (a) The COMSOL solution; (b) comparison with the reduced models at various times during discharge; (c) time-averaged absolute errors; (d) z-averaged absolute errors.
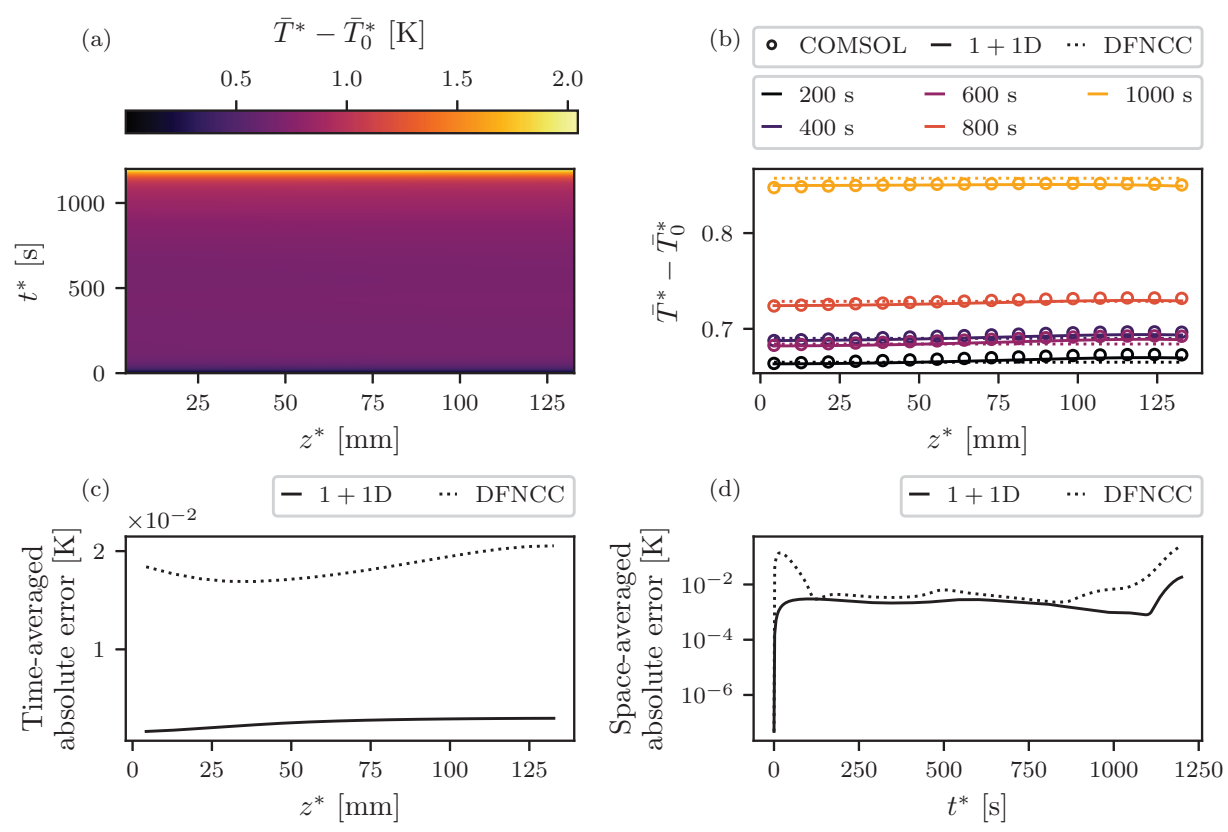

FIG. 5. The x-averaged temperature. (a) The COMSOL solution; (b) comparison with the reduced models at various times during discharge; (c) time-averaged absolute errors; (d) z-averaged absolute errors. 
TABLE 1

Normalized RMS error between the two-dimensional solution in COMSOL and the $1+1 D D F N$ and DFNCC solutions in PyBaMM for a selection of model variables. The tabulated quantities for a variable $\psi$ were computed as $R M S\left(\psi_{P y B a M M}-\psi_{C O M S O L}\right) / R M S\left(\psi_{C O M S O L}\right)$. Here $N$ is the number of mesh cells per spatial dimension in each domain in the $1+1 D$ model. The $1+1 D$ solution was compared to the two-dimensional solution on a "fine" mesh (450 elements in each current collector, 1650 elements in each electrode, 450 elements in the separator) in COMSOL. Both time-stepping routines used a relative and absolute tolerance of $10^{-6}$.

\begin{tabular}{|c|c|c|c|c|c|c|c|c|}
\hline \multicolumn{9}{|c|}{$1+1 \mathrm{D}$} \\
\hline$N$ & $\phi_{\mathrm{s}, \mathrm{cn}}^{*}$ & $\phi_{\mathrm{s}, \mathrm{cp}}^{*}-V^{*}$ & $\bar{c}_{\mathrm{s}, \mathrm{n}, \mathrm{surf}}^{*}$ & $\bar{c}_{\mathrm{s}, \mathrm{p}, \text { surf }}^{*}$ & $\mathcal{I}^{*}$ & $\bar{T}^{*}$ & $V^{*}$ & Solution time $[\mathrm{s}]$ \\
\hline 4 & $2.148 \times 10^{-2}$ & $6.420 \times 10^{-2}$ & $1.646 \times 10^{-2}$ & $2.676 \times 10^{-3}$ & $3.954 \times 10^{-4}$ & $1.024 \times 10^{-4}$ & $2.341 \times 10^{-3}$ & 0.6115 \\
\hline 8 & $5.377 \times 10^{-3}$ & $1.605 \times 10^{-2}$ & $5.767 \times 10^{-3}$ & $7.584 \times 10^{-4}$ & $1.015 \times 10^{-4}$ & $3.030 \times 10^{-5}$ & $6.864 \times 10^{-4}$ & 1.323 \\
\hline 16 & $1.345 \times 10^{-3}$ & $4.011 \times 10^{-3}$ & $1.815 \times 10^{-3}$ & $2.082 \times 10^{-4}$ & $3.249 \times 10^{-5}$ & $7.772 \times 10^{-6}$ & $1.774 \times 10^{-4}$ & 9.446 \\
\hline 32 & $3.421 \times 10^{-4}$ & $1.004 \times 10^{-3}$ & $5.231 \times 10^{-4}$ & $5.459 \times 10^{-5}$ & $2.665 \times 10^{-5}$ & $3.056 \times 10^{-6}$ & $4.412 \times 10^{-5}$ & 85.97 \\
\hline \multicolumn{9}{|c|}{ DFNCC } \\
\hline$N$ & $\phi_{\mathrm{s}, \mathrm{cn}}^{*}$ & $\phi_{\mathrm{s}, \mathrm{cp}}^{*}-V^{*}$ & $\bar{c}_{\mathrm{s}, \mathrm{n}, \text { surf }}^{*}$ & $\bar{c}_{\mathrm{s}, \mathrm{p}, \text { surf }}^{*}$ & $\mathcal{I}^{*}$ & $\bar{T}^{*}$ & $V^{*}$ & Solution time [s] \\
\hline 4 & $2.172 \times 10^{-2}$ & $2.172 \times 10^{-2}$ & $1.650 \times 10^{-2}$ & $2.703 \times 10^{-3}$ & $2.120 \times 10^{-3}$ & $1.202 \times 10^{-4}$ & $2.339 \times 10^{-3}$ & 0.24 \\
\hline 8 & $5.725 \times 10^{-3}$ & $5.725 \times 10^{-3}$ & $5.895 \times 10^{-3}$ & $8.527 \times 10^{-4}$ & $2.294 \times 10^{-3}$ & $8.622 \times 10^{-5}$ & $6.801 \times 10^{-4}$ & 0.41 \\
\hline 16 & $1.948 \times 10^{-3}$ & $1.948 \times 10^{-3}$ & $2.194 \times 10^{-3}$ & $4.437 \times 10^{-4}$ & $2.330 \times 10^{-3}$ & $8.612 \times 10^{-5}$ & $1.728 \times 10^{-4}$ & 0.99 \\
\hline 32 & $1.262 \times 10^{-3}$ & $1.262 \times 10^{-3}$ & $1.241 \times 10^{-3}$ & $3.963 \times 10^{-4}$ & $2.334 \times 10^{-3}$ & $8.724 \times 10^{-5}$ & $4.931 \times 10^{-5}$ & 2.9 \\
\hline
\end{tabular}

each current collector, 1650 elements in each electrode, 450 elements in the separator), which was typically solved in around $5376 \mathrm{~s}$. It can be seen that the error in the through-cell current density $\mathcal{I}^{*}$ for the DFNCC model is much larger than that of the $1+1 \mathrm{D}$ model, and remains unchanged as the mesh is refined; this is the asymptotic error inherent in the model. However, other quantities, such as the terminal voltage, are predicted equally well by the DFNCC model at a fraction of the computation time. Depending on the quantities of interest, the simpler DFNCC model may well be sufficient for a range of applications.

Finally, to illustrate the asymptotic convergence of the DFNCC model we fix $\sigma_{\mathrm{cn}}=\sigma_{\mathrm{cp}}=\sigma$ and solve for a range of values of $\sigma$. The normalized RMS error between the two-dimensional solution in COMSOL and the 1+1D DFN and DFNCC solutions in PyBaMM for a selection of model variables are shown in Figure 6.

5. Conclusions. In this paper, we have provided a systematic asymptotic derivation of the 2+1D DFN battery model from the full three-dimensional DFN model, identifying the key nondimensional parameters controlling the reduction. Our findings are in agreement with other works that employ the $2+1 \mathrm{D}$ approach in an ad-hoc fashion (e.g., $[20,12,22,18]$ ). Moreover, we have shown that, in a suitable parameter regime, the model can be simplified further to the DFNCC comprising a single representative one-dimensional model describing the electrochemistry in the through-cell direction with an uncoupled two-dimensional problem to solve for the distribution of potential in the current collectors, from which resistances and heat generation can be determined. This latter approximation reduces the model from pseudo-fourdimensional to pseudo-two-dimensional, dramatically reducing computational cost.

By identifying the parameters which control the asymptotic reduction, our analysis highlights the parameter regimes in which the 2+1D DFN and DFNCC models are appropriate, and quantifies the error a priori. This in turn informs practical design choices for key cell parameters (such as current collector thickness or tab placement) in order that the cell discharge uniformly. 

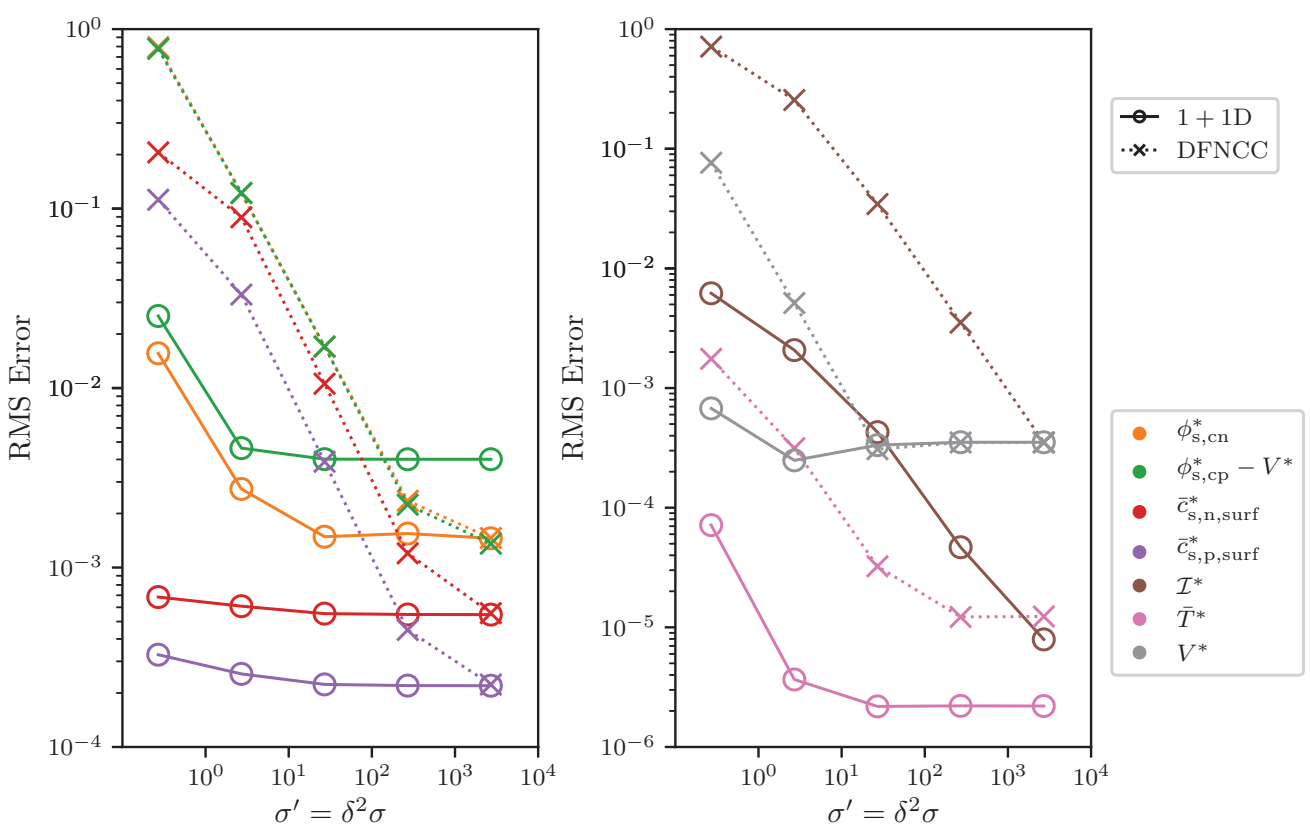

FIG. 6. Normalized RMS error between the two-dimensional solution in COMSOL and the $1+1 D$ DFN and DFNCC solutions in PyBaMM for a selection of model variables as the nondimensional conductivity $\sigma$ is varied, with $\sigma_{c n}=\sigma_{c p}=\sigma$. The quantities plotted for a variable $\psi$ were computed as $R M S\left(\psi_{P y B a M M}-\psi_{C O M S O L}\right) / R M S\left(\psi_{C O M S O L}\right)$.

Our systematic analysis also makes clear that the simplifications are independent of the model used for the through-cell current, so that they can be combined with other through-cell asymptotic simplifications (e.g., reducing the DFN to the single particle model with electrolyte $[23,32])$ in a systematic and mathematically consistent way. This idea is exploited in [24], in which further model reductions are considered in various interesting and physically relevant limits. Of course, more complicated through-cell models can also be used by extending the DFN to include additional physics such as degradation mechanisms, particle size distributions, nonspherical particles, etc. The $2+1 \mathrm{D}$ DFN model provides a framework into which such additional physical effects can be incorporated in a straightforward manner, providing a computationally efficient way of investigating how nonuniform cell use affects degradation, for example, and helping to rapidly assess new cell designs that aim to mitigate nonuniform aging of cells.

Appendix A. Dimensionless parameter values and variables. In Table 2 we provide the values of the dimensionless parameters, calculated from the dimensional parameters provided in Table SM1. In Table 3, we provide a glossary of the dimensionless variables and their region of definition. 


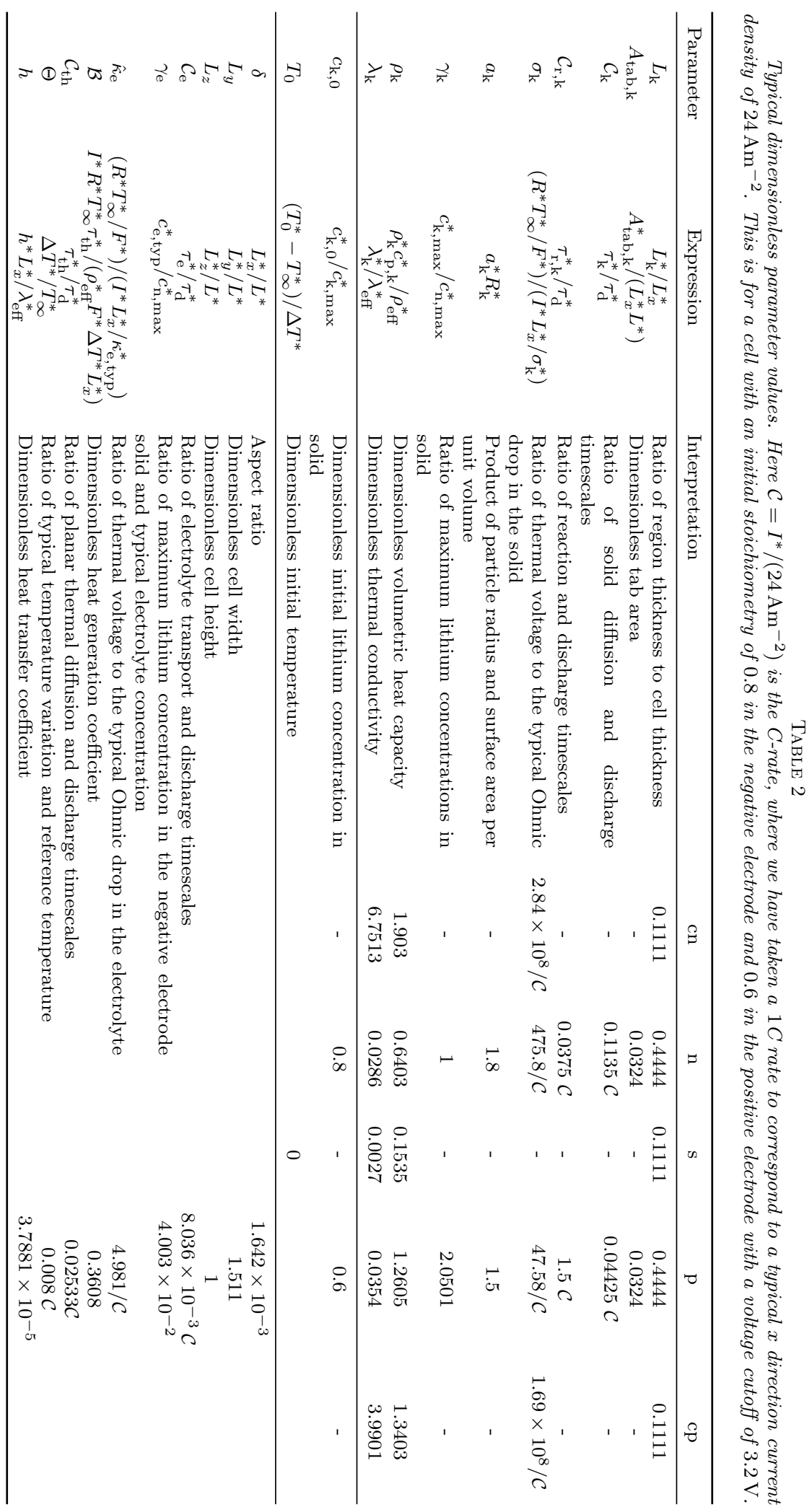


TABLE 3

Dimensionless variables.

\begin{tabular}{clc}
\hline Symbol & Interpretation & Region $\mathrm{k} \in\{\cdots\}$ \\
\hline$\phi_{\mathrm{s}, \mathrm{k}}$ & Electric potential in solid & $\mathrm{cn}, \mathrm{n}, \mathrm{p}, \mathrm{cp}$ \\
$\phi_{\mathrm{e}, \mathrm{k}}$ & Electric potential in the electrolyte & $\mathrm{n}, \mathrm{s}, \mathrm{p}$ \\
$\boldsymbol{i}_{\mathrm{s}, \mathrm{k}}$ & Current density in the solid & $\mathrm{cn}, \mathrm{n}, \mathrm{p}, \mathrm{cp}$ \\
$\boldsymbol{i}_{\mathrm{e}, \mathrm{k}}$ & Current density in the electrolyte & $\mathrm{n}, \mathrm{s}, \mathrm{p}$ \\
$c_{\mathrm{s}, \mathrm{k}}$ & Lithium concentration in the active material & $\mathrm{n}, \mathrm{p}$ \\
$c_{\mathrm{e}, \mathrm{k}}$ & Lithium-ion concentration in the electrolyte & $\mathrm{n}, \mathrm{s}, \mathrm{p}$ \\
$N_{\mathrm{s}, \mathrm{k}}$ & Lithium flux in the active material & $\mathrm{n}, \mathrm{p}$ \\
$\boldsymbol{N}_{\mathrm{e}, \mathrm{k}}$ & Lithium-ion flux in the electrolyte & $\mathrm{n}, \mathrm{s}, \mathrm{p}$ \\
$j_{\mathrm{k}}$ & Interfacial current density & $\mathrm{n}, \mathrm{p}$ \\
$j_{0, \mathrm{k}}$ & Exchange current density & $\mathrm{n}, \mathrm{p}$ \\
$\eta_{\mathrm{k}}$ & Surface reaction overpotential & $\mathrm{n}, \mathrm{p}$ \\
$U_{\mathrm{k}}$ & Open circuit potential & $\mathrm{n}, \mathrm{p}$ \\
$T_{\mathrm{k}}$ & Temperature & $\mathrm{cn}, \mathrm{n}, \mathrm{s}, \mathrm{p}, \mathrm{cp}$ \\
$Q_{\mathrm{Ohm}, \mathrm{k}}$ & Ohmic heating in solid & $\mathrm{cn}, \mathrm{cp}$ \\
$Q_{\mathrm{Ohm}, \mathrm{k}}$ & Combined Ohmic heating in solid and electrolyte & $\mathrm{n}, \mathrm{p}$ \\
$Q_{\mathrm{Ohm}, \mathrm{k}}$ & Ohmic heating in electrolyte & $\mathrm{s}$ \\
$Q_{\mathrm{rxn}, \mathrm{k}}$ & Irreversible heating due to electrochemical reactions & $\mathrm{n}, \mathrm{p}$ \\
$Q_{\mathrm{rev}, \mathrm{k}}$ & Reversible heating due to electrochemical reactions & $\mathrm{n}, \mathrm{p}$ \\
\hline & & \\
\hline
\end{tabular}

\section{REFERENCES}

[1] M. Armand and J. Tarascon, Building better batteries, Nature, 451 (2008), p. 652.

[2] D. Baker and M. Verbrugge, Temperature and current distribution in thin-film batteries, J. Electrochem. Soc., 146 (1999), pp. 2413-2424, https://doi.org/10.1149/1.1391950.

[3] D. Bernardi, E. Pawlikowski, and J. Newman, A general energy balance for battery systems, J. Electrochem. Soc., 132 (1985), pp. 5-12, https://doi.org/10.1149/1.2113792.

[4] C. Birkl, M. Roberts, E. McTurk, P. Bruce, and D. Howey, Degradation diagnostics for lithium ion cells, J. Power Sources, 341 (2017), pp. 373-386.

[5] A. Bizeray, State and Parameter Estimation of Physics-Based Lithium-Ion Battery Models, Ph.D. thesis, University of Oxford, 2016.

6] H. Carslaw and J. Jaeger, Conduction of Heat in Solids, Clarendon Press, 1959.

[7] COMSOL Multiphysics Reference Manual, Version 5.4, COMOSOL Inc., https://www.comsol. com.

[8] M. Doyle, T. Fuller, and J. Newman, Modeling of galvanostatic charge and discharge of the lithium/polymer/insertion cell, J. Electrochem. Soc., 140 (1993), pp. 1526-1533.

[9] S. Erhard, P. Osswald, P. Keil, E. Höffer, M. Haug, A. Noel, J. Wilhelm, B. Rieger, K. Schmidt, S. Kosch ET AL., Simulation and measurement of the current density distribution in lithium-ion batteries by a multi-tab cell approach, J. Electrochem. Soc., 164 (2017), p. A6324.

[10] M. Farag, H. Sweity, M. Fleckenstein, and S. Habibi, Combined electrochemical, heat generation, and thermal model for large prismatic lithium-ion batteries in real-time applications, J. Power Sources, 360 (2017), pp. 618-633, https://doi.org/10.1016/j.jpowsour. 2017.06.031.

[11] T. Fuller, M. Doyle, And J. Newman, Simulation and optimization of the dual lithium ion insertion cell, J. Electrochem. Soc., 141 (1994), pp. 1-10.

[12] R. Gerver AND J. Meyers, Three-dimensional modeling of electrochemical performance and heat generation of lithium-ion batteries in tabbed planar configurations, J. Electrochem. Soc., 158 (2011), pp. A835-A843, https://doi.org/10.1149/1.3591799.

[13] P. Gomadam, J. Weidner, R. Dougal, and R. White, Mathematical modeling of lithium-ion and nickel battery systems, J. Power Sources, 110 (2002), pp. 267-284.

[14] W. Gu And C. Wang, Thermal-electrochemical modeling of battery systems, J. Electrochem. Soc., 147 (2000), pp. 2910-2922.

[15] E. Hosseinzadeh, R. Genieser, D. Worwood, A. Barai, J. Marco, and P. Jennings, A systematic approach for electrochemical-thermal modelling of a large format lithium-ion battery for electric vehicle application, J. Power Sources, 382 (2018), pp. 77-94, https: //doi.org/10.1016/j.jpowsour.2018.02.027.

Copyright (C) by SIAM. Unauthorized reproduction of this article is prohibited. 
[16] I. Hunt, Y. Zhao, Y. Patel, And G. Offer, Surface cooling causes accelerated degradation compared to tab cooling for lithium-ion pouch cells, J. Electrochem. Soc., 163 (2016), pp. A1846-A1852, https://doi.org/10.1149/2.0361609jes.

[17] F. Incropera, D. DeWitt, T. Bergman, and A. Lavine, Fundamentals of Heat and Mass Transfer, John Wiley \& Sons, 2007.

[18] G. Kim, K. Smith, K. Lee, S. Santhanagopalan, and A. Pesaran, Multi-domain modeling of lithium-ion batteries encompassing multi-physics in varied length scales, J. Electrochem. Soc., 158 (2011), pp. A955-A969, https://doi.org/10.1149/1.3597614.

[19] U. KIM, C. SHIN, AND C. KIM, Effect of electrode configuration on the thermal behavior of a lithium-polymer battery, J. Power Sources, 180 (2008), pp. 909-916, https://doi.org/10. 1016/j.jpowsour.2007.09.054.

[20] S. Kosch, Y. Zhao, J. Sturm, J. Schuster, G. Mulder, E. Ayerbe, and A. Jossen, A computationally efficient multi-scale model for lithium-ion cells, J. Electrochem. Soc., 165 (2018), pp. A2374-A2388.

[21] J. Lee, J. Kim, H. Chang, D. Lee, And C. Kim, The effect of tab attachment positions and cell aspect ratio on temperature difference in large-format libs using design of experiments, Energies, 14 (2021), p. 116.

[22] K. Lee, K. Smith, A. Pesaran, and G. Kim, Three dimensional thermal-, electrical-, and electrochemical-coupled model for cylindrical wound large format lithium-ion batteries, J. Power Sources, 241 (2013), pp. 20-32, https://doi.org/10.1016/j.jpowsour.2013.03.007.

[23] S. Marquis, V. Sulzer, R. Timms, C. Please, and S. Chapman, An asymptotic derivation of a single particle model with electrolyte, J. Electrochem. Soc., 166 (2019), pp. A3693-A3706.

[24] S. Marquis, R. Timms, V. Sulzer, C. Please, and S. Chapman, A suite of reduced-order models of a single-layer lithium-ion pouch cell, J. Electrochem. Soc., 167 (2020), 140513.

[25] S. Moura, fastDFN, https://github.com/scott-moura/fastDFN, 2016.

[26] J. Newman and K. Thomas-Alyea, Electrochemical Systems, John Wiley \& Sons, 2012.

[27] J. Newman and C. Tobias, Theoretical analysis of current distribution in porous electrodes, J. Electrochem. Soc., 109 (1962), pp. 1183-1191.

[28] P. Northrop, M. Pathak, D. Rife, S. De, S. Santhanagopalan, and V. Subramanian, Efficient simulation and model reformulation of two-dimensional electrochemical thermal behavior of lithium-ion batteries, J. Electrochem. Soc., 162 (2015), pp. A940-A951, https: //doi.org/10.1149/2.0341506jes.

[29] G. Plett, Battery Management Systems, Volume I: Battery Modeling, Vol. 1, Artech House, 2015.

[30] V. Ramadesigan, P. Northrop, S. De, S. Santhanagopalan, R. Braatz, and V. SubramaNIAN, Modeling and simulation of lithium-ion batteries from a systems engineering perspective, J. Electrochem. Soc., 159 (2012), pp. R31-R45, https://doi.org/10.1149/2.018203jes.

[31] G. Richardson, G. Denuault, and C. Please, Multiscale modelling and analysis of lithiumion battery charge and discharge, J. Engrg. Math., 72 (2012), pp. 41-72.

[32] G. Richardson, I. Korotkin, R. Castle, and J. Foster, Generalised Single Particle Models for High-Rate Operation of Graded Lithium-Ion Electrodes: Systematic Derivation and Validation, preprint, https://arxiv.org/abs/1907.09410, 2019.

[33] B. Rieger, S. Erhard, S. Kosch, M. Venator, A. Rheinfeld, and A. Jossen, Multidimensional modeling of the influence of cell design on temperature, displacement and stress inhomogeneity in large-format lithium-ion cells, J. Electrochem. Soc., 163 (2016), pp. A3099-A3110.

[34] M. Schmuck ANd M. Z. BazAnt, Homogenization of the Poisson-Nernst-Planck equations for ion transport in charged porous media, SIAM J. Appl. Math., 75 (2015), pp. 1369-1401, https://doi.org/10.1137/140968082.

[35] B. Scrosati and J. Garche, Lithium batteries: Status, prospects and future, J. Power Sources, 195 (2010), pp. 2419-2430.

[36] V. Sulzer, Mathematical Modelling of Lead-Acid Batteries, Ph.D. thesis, University of Oxford, 2019.

[37] V. Sulzer, S. Marquis, R. Timms, M. Robinson, and S. Chapman, Python Battery Mathematical Modelling (PyBaMM), preprint, https://doi.org/10.1149/osf.io/67ckj, 2020.

[38] R. VAn Noorden, The rechargeable revolution: A better battery, Nature News, 507 (2014), p. 26.

[39] S. VANimisetti And N. Ramakrishnan, Effect of the electrode particle shape in Li-ion battery on the mechanical degradation during charge-discharge cycling, Proc. Inst. Mech. Engineers Part C J. Mech. Engrg. Sci., 226 (2012), pp. 2192-2213.

[40] C. Wang, W. Gu, And B. Liaw, Micro-macroscopic coupled modeling of batteries and fuel cells: I. Model development, J. Electrochem. Soc., 145 (1998), pp. 3407-3417, https://doi. org/10.1149/1.1838820.

Copyright (c) by SIAM. Unauthorized reproduction of this article is prohibited. 